MINISTÉRIO DA SAÚDE

Secretaria Executiva

Coordenação Nacional de DST e AIDS

\title{
A POLÍTICA DO MINISTÉRIO DA SAÚdE PARA A ATENÇÃO INTEGRAL A USUÁRIOS DE ÁLCOOL E OUTRAS DROGAS
}

Série B. Textos Básicos de Saúde 
(־) 2003. Ministério da Saúde.

É permitida a reprodução parcial ou total desta obra, desde que citada a fonte.

Série B. Textos Básicos de Saúde

Tiragem: 500 exemplares

Informações e Distribuição:

MINISTÉRIO DA SAÚDE

Secretaria Executiva

Esplanada dos Ministérios, bloco G, edifício sede, sala 140

CEP 70058-900, Brasília - DF

Tels.: (61) $3153319 / 3152313$

E-mail: saudemental@saude.gov.br

\section{Elaboração:}

Grupo de Trabalho em Álcool e Outras Drogas

Cláudia Araújo dos Santos, Denise Doneda, Denise Gandolfi, Maria Cristina Hoffmann, Maria Gorete Selau, Margareth Oliveira,

Paulo Macedo, Pedro Gabriel Delgado, Regina Benevides, Sueli Rodrigues

Revisão Técnica:

ATSM/DAPE/SAS/MS

Impresso no Brasil / Printed in Brazil

Brasil. Ministério da Saúde. Secretaria Executiva. Coordenação Nacional de DST/Aids.

A Política do Ministério da Saúde para atenção integral a usuários de álcool e outras drogas / Ministério da Saúde, Secretaria Executiva, Coordenação Nacional de DST e Aids. - Brasília: Ministério da Saúde, 2003.

60 p.: il. - (Série B. Textos Básicos de Saúde)

1. Prestação de Cuidados de Saúde. 2. Alcoolismo. I. Brasil. Ministério da Saúde. II. Brasil. Secretaria Executiva. III. Coordenação Nacional de DST e Aids. IV. Título. V. Série.

NLM W 84 


\section{SUMÁRIO}

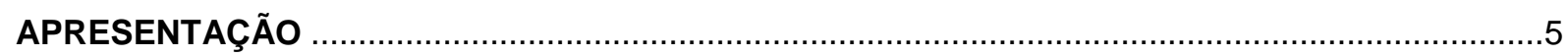

1 - INTRODUÇÃO - O CENÁRIO CONTEMPORANEO ….......................................................

2 - MARCO TEORICO-POLITICO

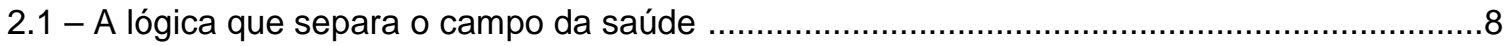

2.2 - A política de atenção integral em álcool e outras drogas ....................................................

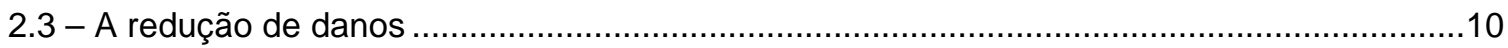

2.4 - A rede de saúde como local de conexão e inserção .......................................................10

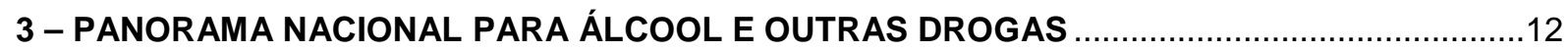

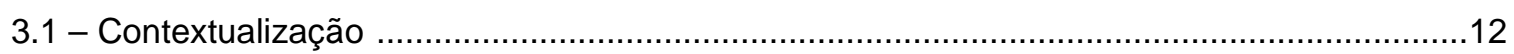

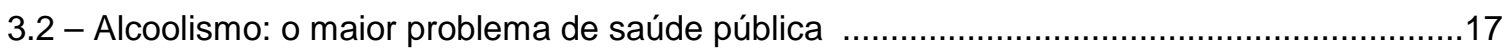

3.3 - Uso de Drogas e início da vida sexual .............................................................................22

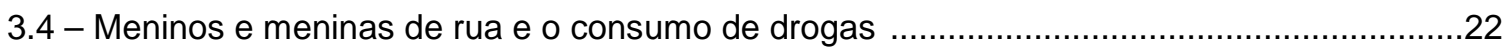

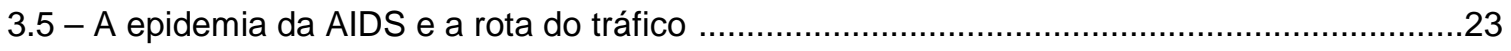

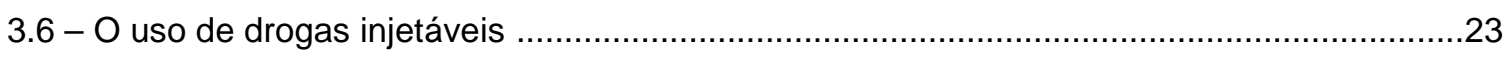

4 - DIRETRIZES PARA UMA POLÍTICA DE ATENÇÃO INTEGRAL AOS USUARIOS DE ÁLCOOL E

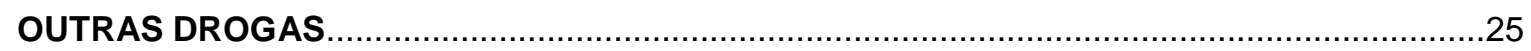

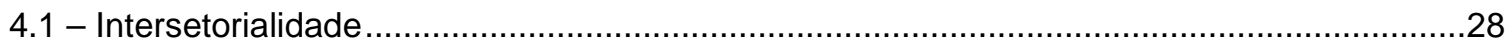

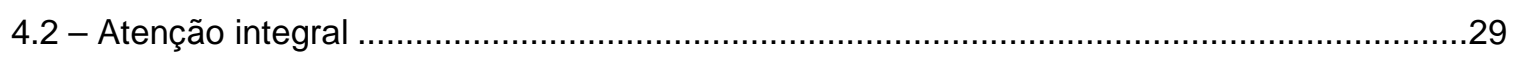

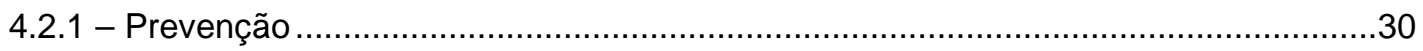

4.2.2 - Promoção e proteção ah saúde de consumidores de álcool e outras drogas ..........35

4.2.3 - Modelos de atenção - CAPS e redes assistenciais ..............................................38

4.2.4 - Controle de entorpecentes - padronização de serviços ........................................45

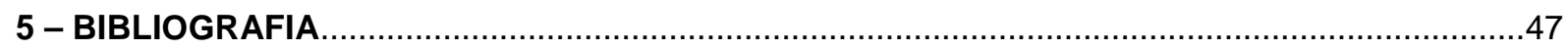

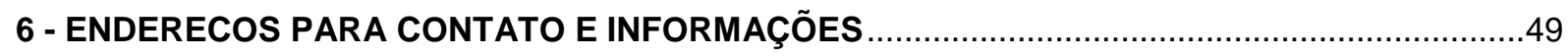





\section{APRESENTAÇÃO}

A ausência de cuidados que atinge, de forma histórica e contínua, aqueles que sofrem de exclusão desigual pelos serviços de saúde, aponta para a necessidade da reversão de modelos assistenciais que não contemplem as reais necessidades de uma população, o que implica em disposição para atender igualmente ao direito de cada cidadão. Tal lógica também deve ser contemplada pelo planejamento de ações voltadas para a atenção integral as pessoas que consomem álcool e outras drogas.

A constatação de que tal uso tomou proporção de grave problema de saúde pública no país encontra ressonância nos diversos segmentos da sociedade, pela relação comprovada entre o consumo e agravos sociais que dele decorrem ou que o reforçam. $O$ enfrentamento desta problemática constitui uma demanda mundial: de acordo com a Organização Mundial de Saúde, cerca de 10\% das populações dos centros urbanos de todo o mundo, consomem abusivamente substâncias psicoativas, independentemente da idade, sexo, nível de instrução e poder aquisitivo. Salvo variações sem repercussão epidemiológica significativa, esta realidade encontra equivalência em território brasileiro.

Uma ação política racional pode melhorar o nível de problemas relacionados ao consumo de álcool e outras drogas que é vivenciado por uma sociedade, evitando que se assista de forma passiva ao fluxo e refluxo de tal problemática; consideramos assim que nada assume um caráter inevitável, mediante uma rápida comparação com o sofrimento global trazido por este consumo. Se em alguns paises impera a total ausência de qualquer iniciativa de saúde publica que tenha este propósito, vemos que em outros tal resposta assume um caráter diversificado, enérgico, meramente retórico e, por vezes, confuso. Vale a pena assinalar que, no vácuo de propostas concretas, e na ausência do estabelecimento de uma clara política de saúde voltada para este segmento, surgiram no Brasil diversas "alternativas de atenção" de caráter total, fechado e tendo como único objetivo a ser alcançado a abstinência.

Porém, a sociedade atual nos disponibiliza uma extensa gama de políticas potenciais, e a sua inventividade e alcance estão em um processo de expansão continua, sendo então possíveis outras formas de produzir novas possibilidades de vida para aqueles que sofrem devido ao consumo de álcool e drogas. Tal produção não ocorre somente por leis, planos ou propostas, e sim pela sua implementação e exercício no cotidiano dos serviços, práticas e instituições, com a definição sistematizada de responsabilidades para cada esfera governamental.

O Sistema Único de Saúde, instituído pela Lei 8080/90, é o conjunto de ações e serviços de saúde que têm por finalidade a promoção de maior qualidade de vida para toda a população brasileira; no intuito de garantir o acesso de todos a uma assistência integral e eqüitativa à Saúde, avança de forma consistente na consolidação de rede de cuidados que funcione de forma regionalizada, hierarquizada e integrada. $O$ SUS tem seu funcionamento organizado pelas Leis 8.080/90 e 8.142/90, editadas com a função de fazer cumprir o mandamento constitucional de dispor legalmente sobre a proteção e a defesa da saúde.

O texto da Lei 10.216 de 06 de abril de 2001, marco legal da Reforma Psiquiátrica, ratificou, de forma histórica, as diretrizes básicas que constituem o Sistema Único de Saúde; garantindo aos usuários de 
serviços de saúde mental - e, conseqüentemente, aos que sofrem por transtornos decorrentes do consumo de álcool e outras drogas - a universalidade de acesso e direito à assistência, bem como à sua integralidade; valoriza a descentralização do modelo de atendimento, quando determina a estruturação de serviços mais próximos do convívio social de seus usuários, configurando redes assistenciais mais atentas às desigualdades existentes, ajustando de forma equânime e democrática as suas ações às necessidades da população.

As conferências de saúde, definidas e instituídas pela Lei 8.142/90, têm como atribuição avaliar a situação da saúde, propondo diretrizes para a formulação de políticas afins, nas três esferas de governo. De forma análoga, as conferencias de saúde mental constituem o foro maior de debates em torno de questões relacionadas a esta área especifica de atuação. Nesta condição, vemos o relatório da III Conferência Nacional de Saúde Mental (dezembro de 2001) evidenciando, de forma ética e diretiva, a (re)afirmação e (re)elaboração de estratégias e propostas para efetivar e consolidar um modelo de atenção aos usuários de álcool e outras drogas que garanta o seu atendimento pelo SUS e, ao mesmo tempo, considere o seu caráter multifatorial, não reduzindo esta questão a uma problemática exclusiva do sistema de atenção à saúde.

Assim sendo, torna-se imperativa a necessidade de estruturação e fortalecimento de uma rede de assistência centrada na atenção comunitária associada à rede de serviços de saúde e sociais, que tenha ênfase na reabilitação e reinserção social dos seus usuários, sempre considerando que a oferta de cuidados a pessoas que apresentem problemas decorrentes do uso de álcool e outras drogas deve ser baseada em dispositivos extra-hospitalares de atenção psicossocial especializada, devidamente articulados à rede assistencial em saúde mental e ao restante da rede de saúde. Tais dispositivos devem fazer uso deliberado e eficaz dos conceitos de território e rede, bem como da lógica ampliada de redução de danos, realizando uma procura ativa e sistemática das necessidades a serem atendidas, de forma integrada ao meio cultural e à comunidade em que estão inseridos, e de acordo com os princípios da Reforma Psiquiátrica.

Neste sentido, entendemos que uma política de prevenção, tratamento e de educação voltada para o uso de álcool e outras drogas deverá necessariamente ser construída nas interfaces intra-setoriais possíveis aos Programas do Ministério da Saúde, o mesmo ocorrendo em relação a outros Ministérios, organizações governamentais e não-governamentais e demais representações e setores da sociedade civil organizada, assegurando a participação intersetorial. Para tanto, decisão política e visão social são elementos indispensáveis.

Reafirmando que o uso de álcool e outras drogas é um grave problema de saúde pública, reconhecendo a necessidade de superar o atraso histórico de assunção desta responsabilidade pelo SUS, e buscando subsidiar a construção coletiva de seu enfrentamento, o Ministério da Saúde apresenta a sua Política para a Atenção Integral ao Uso de Álcool e Outras Drogas.

HUMBERTO COSTA

Ministro da Saúde 


\section{A POLÍTICA DO MINISTÉRIO DA SAÚDE PARA A ATENÇÃO INTEGRAL A USUÁRIOS DE ÁLCOOL E OUTRAS DROGAS}

\section{INTRODUÇÃO}

A realidade contemporânea tem colocado novos desafios no modo como certos temas têm sido habitualmente abordados, especialmente no campo da saúde. Isto se dá pelo fato de que os objetos sobre os quais intervimos apresentam-se complexos, exigindo de nós o esforço de evitarmos simplificações reducionistas. Este é o caso do tema "álcool e outras drogas", que nos indica a necessidade de uma ação não apenas ampliada, mas para onde devem concorrer diferentes saberes e aportes teórico-técnicos. Assim, ao estabelecermos diretrizes, ações e metas na constituição de políticas para o Ministério da Saúde para os próximos anos, deveremos ter em mente a perspectiva transversalizadora que permite a apreensão do fenômeno contemporâneo do uso abusivo/dependência em álcool e outras drogas de modo integrado, e diversificado em ofertas terapêuticas, preventivas, reabilitadoras, educativas e promotoras da saúde.

Historicamente, a questão do uso abusivo e/ou dependência de álcool e outras drogas tem sido abordada por uma ótica predominantemente psiquiátrica ou médica. As implicações sociais, psicológicas, econômicas e políticas são evidentes, e devem ser consideradas na compreensão global do problema. Cabe ainda destacar que o tema vem sendo associado à criminalidade e práticas antisociais e à oferta de "tratamentos" inspirados em modelos de exclusão/separação dos usuários do convívio social. Constatamos assim que, neste vácuo de propostas e de estabelecimento de uma clara política de saúde por parte do Ministério da Saúde, constituíram-se "alternativas de atenção" de caráter total, fechado e tendo como principal objetivo a ser alcançado a abstinência. A percepção distorcida da realidade do uso de álcool e outras drogas promove a disseminação de uma cultura de combate a substâncias que são inertes por natureza, fazendo com que o indivíduo e o seu meio de convívio fiquem aparentemente relegados a um plano menos importante. Isto por vezes é confirmado pela multiplicidade de propostas e abordagens preventivas / terapêuticas consideravelmente ineficazes, por vezes reforçadoras da própria situação de uso abusivo e/ou dependência.

Os principais limites observados pela não priorização, por parte do MS, de uma política de saúde integral dirigida ao consumidor de álcool e outras drogas, podem ser percebidos a partir do impacto econômico e social que tem recaído para o Sistema Único de Saúde - SUS, seja por seus custos diretos, seja pela impossibilidade de resposta de outras pastas governamentais voltadas para um efeito positivo sobre a redução do consumo de drogas; isto também ocorre no que se refere ao resgate do usuário do ponto de vista da saúde (e não tão somente moralista ou legalista), e em estratégias de comunicação que reforçam o senso comum de que todo consumidor é marginal e perigoso para a sociedade. Internamente à Saúde, ressalta-se a elaboração pregressa de políticas fragmentadas, sem capilaridade local e de pouca abrangência, além do desenvolvimento de ações de redução de danos adstritas ao controle da epidemia de AIDS, não explorando as suas possibilidades para a prevenção e a assistência. 
Entendemos que uma política de prevenção, tratamento e de educação para o uso consumo de álcool e outras drogas necessariamente terá que ser construída na interface de programas do Ministério da Saúde com outros Ministérios, bem como com setores da sociedade civil organizada. Trata-se aqui, de afirmar que o consumo de álcool e outras drogas é um grave problema de saúde pública. Dentro de uma perspectiva de saúde pública, o planejamento de programas deve contemplar grandes parcelas da população, de uma forma que a abstinência não seja a única meta viável e possível aos usuários.

A dependência das drogas é transtorno onde predomina a heterogeneidade, já que afeta as pessoas de diferentes maneiras, por diferentes razões, em diferentes contextos e circunstâncias. Muitos consumidores de drogas não compartilham da expectativa e desejo de abstinência dos profissionais de saúde, e abandonam os serviços. Outros sequer procuram tais serviços, pois não se sentem acolhidos em suas diferenças. Assim, o nível de adesão ao tratamento ou a práticas preventivas e de promoção é baixo, não contribuindo para a inserção social e familiar do usuário. Temos ainda presenciado o aparecimento de novas substâncias de abuso e novas formas de consumo, que adotam características próprias e requerem modalidades de prevenção adaptadas aos consumidores e aos contextos onde são consumidas.

Reconhecer o consumidor, suas características e necessidades, assim como as vias de administração de drogas, exige a busca de novas estratégias de contato e de vínculo com ele e seus familiares, para que se possa desenhar e implantar múltiplos programas de prevenção, educação, tratamento e promoção adaptados às diferentes necessidades. Para que uma política de saúde seja coerente, eficaz e efetiva, deve ter em conta que as distintas estratégias são complementares e não concorrentes, e que, portanto, o retardo do consumo de drogas, a redução dos danos associada ao consumo e a superação do consumo são elementos fundamentais para sua construção.

\section{MARCO TEÓRICO-POLÍTICO}

\subsection{A lógica que separa o campo da saúde}

Sempre foi um desafio para as práticas de saúde aliar o âmbito clínico de intervenção com o da saúde coletiva. O primeiro tem como seu foco as manifestações individuais das alterações da saúde, enquanto que o segundo efetua um outro tipo de corte, tomando a incidência e a prevalência das alterações em plano coletivo. Menos do que contribuir para o avanço de dispositivos e instrumentos de diagnóstico, tratamento e reabilitação, promoção e prevenção, esta divisão entre a clínica de um lado, e a saúde coletiva, de outro, tem resultado em embates de saber/poder que (re)afirmam suas verdades em campos separados e, grande parte das vezes, oponentes.

Quando seguimos esta lógica, a das binarizações, todos perdemos. Perdemos as contribuições da experiência clínica que está voltada para as características singulares que se expressam em cada corpo, em cada sujeito, em cada história de vida. Perdemos as contribuições das análises propiciadas pelo recorte da saúde coletiva que capta as expressões de uma comunidade, de uma localidade, de um tipo 
de afecção, de uma categoria social ou de gênero, de histórias que se cruzam configurando a história em um certo momento.

O que estamos querendo aqui destacar é: esta lógica deve ser combatida em prol de uma outra maneira de pensar e fazer que experimente as diferentes contribuições, fazendo-as interpelações umas das outras. A esta outra lógica chamamos transversalização.

Parece que hoje aí reside o grande desafio: instaurar em todos os campos da saúde pública uma atitude que, ao mesmo tempo, garanta as especificidades acumuladas ao longo do tempo em cada núcleo de saber e, para além disso, consiga fazer atravessar tais saberes uns sobre os outros, de modo a construir novos olhares, novos dispositivos de intervenção.

Quem ganha com isto? Os usuários do sistema de saúde e todos aqueles comprometidos com a saúde enquanto defesa da vida.

\subsection{A Política de Atenção integral em álcool e outras drogas}

No campo da política de atenção integral em álcool e outras drogas no Brasil, vimos que o tema tem sido tratado de modo pontual, contando com esforços de setores e grupos preocupados com o aumento exponencial do problema do uso abusivo de álcool de outras drogas. É importante, portanto, destacar que, neste governo, o Ministério da Saúde assume de modo integral e articulado o desafio de prevenir, tratar, reabilitar os usuários de álcool e outras drogas como um problema de saúde pública. sta decisão atende às propostas que foram enfaticamente recomendadas pela III Conferencia Nacional de Saúde Mental, em dezembro de 2001. (III CNSM, Relatório Final, 2001)

Comprometer-se com a formulação, execução e avaliação de uma política de atenção a usuários de álcool e outras drogas exige exatamente a ruptura de uma lógica binarizante que separa e detém o problema em fronteiras rigidamente delineadas, e cujo eixo principal de entendimento (e, portanto, de "tratamento") baseia-se na associação drogas-comportamento anti-social (álcool) ou criminoso (drogas ilícitas). Em ambos os casos, há um único objetivo a ser alcançado: a abstinência.

Frente a este objetivo, são traçadas estratégias de abordagem para sua consecução: redução da oferta e redução da demanda. Para a primeira estratégia, conta-se com a ação da justiça, da segurança e da defesa. Para a segunda, a operação substancial tem-se dado através de tratamentos de internação com afastamento do usuário do agente indutor.

Sem que deixemos de considerar a existência destes métodos, com os quais temos ainda muito que debater, queremos indicar que, em se tratando de tema tão complexo, com claras implicações sociais, psicológicas, econômicas e políticas, traçar uma política com base em um único objetivo é trabalhar em saúde com um modo estreito de entendimento. 
Parece-nos que aí é o sentido da clínica que se perde e, mais ainda, é a riqueza do que nos oferece a saúde coletiva que se empobrece. Queremos resgatar aqui o duplo sentido da clínica: o de "inclinar-se" (klinikós), acolhendo o paciente e sua história, e o de produzir um desvio (clinamem) para produzir outra história, outra possibilidade de existência (Benevides, 2001) Queremos também resgatar o sentido de saúde coletiva que "implica em levar em conta a diversidade e especificidade dos grupos populacionais e das individualidades com seus modos próprios de adoecer e/ou representarem tal processo" (Paim, 1980).

Se nas práticas de saúde nosso compromisso ético é o da defesa da vida, temos que nos colocar na condição de acolhimento, onde cada vida se expressará de uma maneira singular, mas também onde cada vida é expressão da história de muitas vidas, de um coletivo. Não podemos nos afastar deste intrincado ponto onde as vidas, em seu processo de expansão, muitas vezes sucumbem ao aprisionamento, perdem-se de seu movimento de abertura e precisam, para desviar do rumo muitas vezes visto como inexorável no uso de drogas, de novos agenciamentos e outras construções.

\subsection{A redução de danos}

A abstinência não pode ser, então, o único objetivo a ser alcançado. Aliás, quando se trata de cuidar de vidas humanas, temos que, necessariamente, lidar com as singularidades, com as diferentes possibilidades e escolhas que são feitas. As práticas de saúde, em qualquer nível de ocorrência, devem levar em conta esta diversidade. Devem acolher, sem julgamento, o que em cada situação, com cada usuário, é possível, o que é necessário, o que está sendo demandado, o que pode ser ofertado, o que deve ser feito, sempre estimulando a sua participação e o seu engajamento.

Aqui a abordagem da redução de danos nos oferece um caminho promissor. E por que? Porque reconhece cada usuário em suas singularidades, traça com ele estratégias que estão voltadas não para a abstinência como objetivo a ser alcançado, mas para a defesa de sua vida. Vemos aqui que a redução de danos oferece-se como um método (no sentido de methodos, caminho) e, portanto, não excludente de outros. Mas, vemos também, que o método está vinculado à direção do tratamento e, aqui, tratar significa aumentar o grau de liberdade, de co-responsabilidade daquele que está se tratando. Implica, por outro lado, no estabelecimento de vínculo com os profissionais, que também passam a ser coresponsáveis pelos caminhos a serem construídos pela vida daquele usuário, pelas muitas vidas que a ele se ligam e pelas que nele se expressam.

\subsection{A rede de saúde como local de conexão e de inserção}

Se afirmamos que a redução de danos é uma estratégia, é porque entendemos que, enquanto tal, e para ter a eficácia que pretende, ela deve ser operada em inter-ações, promovendo o aumento de superfície de contato, criando pontos de referência, viabilizando o acesso e o acolhimento, adscrevendo a clientela 
e qualificando a demanda, multiplicando as possibilidades de enfrentamento ao problema da dependência no uso do álcool e outras drogas.

Neste ponto, a abordagem se afirma como clínico-política, pois, para que não reste apenas como "mudança comportamental", a redução de danos deve se dar como ação no território, intervindo na construção de redes de suporte social, com clara pretensão de criar outros movimentos possíveis na cidade, visando avançar em graus de autonomia dos usuários e seus familiares, de modo a lidar com a hetero e a autoviolência muitas vezes decorrentes do uso abusivo do álcool e outras drogas, usando recursos que não sejam repressivos, mas comprometidos com a defesa da vida. Neste sentido, o locus de ação pode ser tanto os diferentes locais por onde circulam os usuários de álcool e outras drogas, como equipamentos de saúde flexíveis, abertos, articulados com outros pontos da rede de saúde, mas também das de educação, de trabalho, de promoção social etc., equipamentos em que a promoção, a prevenção, o tratamento e reabilitação sejam contínuos e se dêem de forma associada.

Nunca é demais, portanto, insistir que é a rede - de profissionais, de familiares, de organizações governamentais e não-governamentais em interação constante, cada um com seu núcleo específico de ação, mas apoiando-se mutuamente, alimentando-se enquanto rede - que cria acessos variados, acolhe, encaminha, previne, trata, reconstrói existências, cria efetivas alternativas de combate ao que, no uso das drogas, destrói a vida.

Este é o compromisso da saúde: fazer proliferar a vida, e fazê-la digna de ser vivida. Este é o compromisso do Ministério da Saúde: criar e manter equipamentos, qualificar seus profissionais, formular políticas de saúde em articulação com outras áreas afins, executar e avaliar tais políticas assumindo o que lhe cabe no enfrentamento do que faz adoecer e morrer. Este é o compromisso do SUS: fortalecer seu caráter de rede incitando outras redes à conexão. A garantia do acesso aos serviços e à participação do consumidor em seu tratamento são princípios assumidos pelo SUS como direitos a serem garantidos. Isto se dá através do estabelecimento de vínculos, da construção da coresponsabilidade e de uma perspectiva ampliada da clínica, transformando os serviços em locais de acolhimento e enfrentamento coletivo das situações ligadas ao problema.

Proporcionar tratamento na atenção primária, garantir o acesso a medicamentos, garantir atenção na comunidade, fornecer educação em saúde para a população, envolver comunidades / famílias / usuários, formar recursos humanos, criar vínculos com outros setores, monitorizar a saúde mental na comunidade, dar mais apoio à pesquisa e estabelecer programas específicos são práticas que devem ser obrigatoriamente contempladas pela Política de Atenção a Usuários de Álcool e Outras Drogas, em uma perspectiva ampliada de saúde pública. 


\section{PANORAMA NACIONAL PARA ÁLCOOL E OUTRAS DROGAS}

\subsection{Contextualização}

A exclusão social e a ausência de cuidados que atingem, de forma histórica e contínua, aqueles que sofrem de transtornos mentais, apontam para a necessidade da reversão de modelos assistenciais que não contemplam as reais necessidades de uma população. Isto é uma demanda mundial, amplamente respaldada por evidências científicas. Citando somente um exemplo, dados fornecidos por estudo capitaneado pela Universidade de Harvard indicam que, das dez doenças mais incapacitantes em todo o mundo, cinco são de origem psiquiátrica: depressão, transtorno afetivo bipolar, alcoolismo, esquizofrenia e transtorno obsessivo-compulsivo (Murray e Lopez, 1996). Apesar de responsáveis diretas por somente $1,4 \%$ de todas as mortes, as condições neurológicas e psiquiátricas foram responsáveis por $28 \%$ de todos os anos vividos com alguma desabilitação para a vida. Salvo variações sem repercussão epidemiológica significativa, a realidade acima encontra equivalência em território brasileiro.

De acordo com a própria Organização Mundial de Saúde (OMS, 2001), cerca de 10\% das populações dos centros urbanos de todo o mundo, consomem abusivamente substâncias psicoativas independentemente da idade, sexo, nível de instrução e poder aquisitivo. A despeito do uso de substâncias psicoativas de caráter ilícito, e considerando qualquer faixa etária, o uso indevido de álcool e tabaco tem a maior prevalência global, trazendo também as mais graves conseqüências para a saúde pública mundial. Corroborando tais afirmações, estudo conduzido pela Universidade de Harvard e instituições colaboradoras (Murray e Lopez, 1996) sobre a carga global de doenças trouxe a estimativa de que o álcool seria responsável por cerca de $1,5 \%$ de todas as mortes no mundo, bem como sobre $2,5 \%$ do total de anos vividos ajustados para incapacidade. Ainda segundo o mesmo estudo, esta carga inclui transtornos físicos (cirrose hepática, miocardiopatia alcoólica, etc) e lesões decorrentes de acidentes (industriais e automobilísticos, por exemplo) influenciados pelo uso indevido de álcool, o qual cresce de forma preocupante em países em desenvolvimento.

O uso do álcool é cultural, sendo permitido em quase todas as sociedades do mundo. Informações sobre "saber beber com responsabilidade e as conseqüências do uso inadequado de álcool", ainda são insuficientes e não contemplam a população de maior risco para o consumo, que são os adolescentes e os adultos jovens.

Os transtornos mentais e de comportamento têm ocorrência relativamente comum durante a infância e adolescência (OMS, 2001). Com freqüência, não são detectados, mesmo porque existe um certo consenso popular sobre a sua inexistência, ou mesmo sobre um suposto caráter incomum. Apesar disso, trazem custo inestimável para a sociedade como um todo, especialmente nos aspectos humano e financeiro. Constituem grave problema de saúde pública mundial, o que se agrava pelo fato de que muitos dos transtornos ocorridos nestas fases do desenvolvimento humano podem continuar se manifestando durante a idade adulta, em um comprometimento global de estimativa complexa e difícil; 
geram grande carga agregada de doenças, sendo freqüentemente o reflexo de acometimento maior, em um contexto sócio-familiar.

Ainda que apresentem variação considerável, estudos investigativos evidenciam uma prevalência geral elevada de transtornos mentais e de comportamento em crianças - 10 a $20 \%$ delas podem ter um ou mais problemas mentais. Porém, enquanto fases do desenvolvimento, a infância e a adolescência não proporcionam uma clara delineação / delimitação entre fenômenos tidos como anormais, e outros aceitos como componentes de um desenvolvimento normal, o que certamente superestima a prevalência acima mencionada. Em contrapartida, vemos uma elevação na identificação de transtornos que, freqüentemente observados em adultos, podem ter seu início na idade infantil, como no caso dos transtornos depressivos. No tocante a categorias diagnósticas específicas da infância e adolescência (CID-10, 1996), vemos que transtornos hipercinéticos, distúrbios de atenção e hiperatividade, distúrbios de conduta e transtornos emocionais da infância podem constituir fatores de risco para a ocorrência futura de comorbidades diversas - especialmente, o uso de álcool e outras drogas.

Existe uma tendência mundial que aponta para o uso cada vez mais precoce de substâncias psicoativas, incluindo o álcool, sendo que tal uso também ocorre de forma cada vez mais pesada. No Brasil, estudo realizado pelo CEBRID - Centro Brasileiro de Informações sobre Drogas Psicoativas sobre o uso indevido de drogas por estudantes $(n=2.730)$ dos antigos $1^{\circ}$ e $2^{\circ}$ graus em 10 capitais brasileiras (Galduróz et. al., 1997) revelou percentual altíssimo de adolescentes que já haviam feito uso de álcool na vida: $74,1 \%$. Quanto a uso freqüente, e para a mesma amostra, chegamos a $14,7 \%$. Ficou constatado que $19,5 \%$ dos estudantes faltaram à escola, após beber, e que 11,5\% brigaram, sob o efeito do álcool.

Como conseqüências, temos altos índices de abandono escolar, bem como o rompimento de outros laços sociais que reforçam a percepção pública deste uso como próximo ao crime, faltando a compreensão do fenômeno como reflexo de questões multifatoriais.

Comparativamente a estudos semelhantes realizados anteriormente, com o mesmo rigor metodológico (o que permite algum nível comparativo, visto que se referem a grupos populacionais definidos), o uso freqüente de álcool aumentou em seis capitais, e o uso pesado (20 vezes ou mais por mês) aumentou em oito das dez capitais participantes do estudo.

Estudos como este encontram dificuldades para a sua replicação em ambientes escolares de natureza privada, o que se justifica por diversas razões; dentre elas, destacamos o temor (por parte de diretores e donos de escolas) de que, mediante divulgação indevida dos dados obtidos, estes estabelecimentos de ensino fiquem de alguma forma estigmatizados como locais nos quais haveria uma suposta facilitação ao uso de substâncias psicoativas, o que supostamente teria impacto indesejado sobre a credibilidade da escola, enquanto um espaço de formação de sujeitos.

Ao considerarmos crianças e adolescentes em situação de rua, vemos um agravamento da situação acima descrita, no tocante às substâncias psicoativas em geral (Noto et. al., 1993), sendo apresentados 
percentuais altíssimos de uso na vida, em todas as capitais pesquisadas, também de forma cada vez mais precoce e pesada.

Diversos estudos brasileiros têm apontado o crescimento do consumo de álcool entre jovens. Dados do "Levantamento Sobre o Uso de Drogas com Estudantes de 1ํ e 20 Grau em 10 Capitais Brasileiras" realizada pelo Centro Brasileiro de Informações sobre Drogas Psicotrópicas (CEBRID), apontam que o uso de drogas psicotrópicas entre estudantes da rede pública de ensino vem aumentando significativamente, ao longo do período de 1987 a 1997. Nas camadas mais pobres da população, o uso de solventes e maconha é observado com freqüência.

Observa-se também o aumento no uso de ansiolíticos, anfetaminas e cocaína. Comparando-se o aumento do consumo destas substâncias ao longo dos quatro levantamentos, na categoria de uso "seis vezes ou mais no mês", observou-se aumento no consumo de $100 \%$ para os ansiolíticos; $150 \%$ para as anfetaminas; $325 \%$ para a maconha e $700 \%$ para a cocaína.

A resposta nacional à epidemia de AIDS aumentou a visibilidade dos usuários de drogas injetáveis, pela alta taxa de compartilhamento de seringas e agulhas. Cerca $25 \%$ dos casos de AIDS estão direta ou indiretamente relacionados a categoria de exposição uso de drogas injetáveis. Estudo realizado entre UDIs acessados por projetos de redução de danos (Pesquisa AJUDE Brasil II - 2001) apontam que $38,6 \%$ concederam agulhas e seringas a outra pessoa, enquanto $35,9 \%$ utilizaram agulhas/seringas de outra pessoa . A taxa de soroprevalência de HIV é de $36,5 \%$.

Pesquisa encomendada pelo Governo Federal sobre os custos dos acidentes de trânsito no Brasil (IPEA/MS e Cols., em desenvolvimento), mostra em seus resultados preliminares que $53 \%$ do total dos pacientes atendidos por acidentes de trânsito, no Ambulatório de Emergência do Hospital das Clínicas/SP, em período determinado, estavam com índices de alcoolemia em seus exames de sangue superiores aos permitidos pelo Código de Trânsito Brasileiro, sendo a maioria pacientes do sexo masculino, com idades entre 15 e 29 anos. A deseconomia relacionada a estes agravos faz com que o SUS gaste aproximadamente $R \$ 1.000 .000,00$ dos recursos do tesouro nacional e do Seguro Obrigatório de Danos Pessoais por Veículos Automotores Terrestres/DPVAT, com internações e tratamentos (IPEA/MS e Cols., em desenvolvimento), a mortalidade chega a 30 mil óbitos/ano, cerca de $28 \%$, das mortes por todas as causas externas. Das análises em vítimas fatais/IML/SP, o nível de alcoolemia encontrado chega a $96,8 \%$.

A relação entre o uso do álcool, outras drogas e os eventos acidentais ou situações de violência, evidencia o aumento na gravidade das lesões e a diminuição dos anos potenciais de vida da população, expondo as pessoas a comportamentos de risco. Os acidentes e violências ocupam a $2^{\text {a }}$ causa de mortalidade geral, sendo a primeira causa de óbitos entre pessoas de 10 a 49 anos de idade. Esse perfil 
se mantém nas séries históricas do Sistema de Mortalidade do Ministério da Saúde, nos últimos oito anos.

O tema "Violência e Saúde" é objeto de estudos nacionais, e internacionais, sendo o Brasil citado pela Organização das Nações Unidas como um dos poucos países que tratam esse assunto no âmbito do setor saúde. O Ministério da Saúde estuda a relação desses agravos com o uso de álcool e outras drogas, para desenvolver a atenção integral à população, de acordo com o estabelecido na Legislação em vigor para o Sistema Único de Saúde (MS, 2001).

O Brasil conta com mais de 51 milhões de jovens na faixa etária dos 10 aos 24 anos de idade. Enfrentar o desafio de promover o desenvolvimento saudável da juventude requer a elaboração de políticas capazes de prover a atenção à saúde em todos os níveis de complexidade, e a participação de todos os setores da sociedade.

O uso de drogas, inclusive álcool e tabaco, tem relação direta e indireta com uma série de agravos à saúde dos adolescentes e jovens, entre os quais destacam-se os acidentes de trânsito, as agressões, depressões clínicas e distúrbios de conduta, ao lado de comportamento de risco no âmbito sexual e a transmissão do HIV pelo uso de drogas injetáveis e de outros problemas de saúde decorrentes dos componentes da substância ingerida, e das vias de administração.

Vários trabalhos citados por Galduróz, Noto e Carlini na discussão do IV Levantamento Sobre o Uso de Drogas entre Estudantes de $1^{\circ}$ e $2^{\circ}$ graus em 10 Capitais Brasileiras evidenciam que o uso de drogas psicotrópicas influem fortemente no baixo rendimento escolar. Tal conclusão foi possível, porque houve diferenças significativas na comparação da defasagem série/idade entre os não usuários e os usuários de drogas, exceto tabaco e álcool. No entanto, a defasagem no país é tão grande que, mesmo sem o uso de drogas, a análise mais aprofundada fica comprometida. Em Salvador, a defasagem chegou a 78,7\%. Com exceção de Porto Alegre, São Paulo e Curitiba, as outras 07 capitais apresentaram defasagem escolar acima de $60 \%$. 


\section{Morbidade Hospitalar do SUS - por local de residência - Brasil}

\section{Internações por Lista Morb CID-10 E Faixa Etária 2}

Faixa Etária 2: 10 a 14 anos, 15 a 19 anos, 20 a 24 anos

Sexo: Masculino/ 2001

\begin{tabular}{|c|c|c|c|c|c|}
\hline Lista Morb CID-10 & 10 a 14 anos & 15 a 19 anos & 20 a 24 anos & Total & $\%$ \\
\hline 1- Lesões enven e alg out conseq causas externas & 36.901 & 44.692 & 53.940 & 135.533 & 24,53 \\
\hline 2- Doenças do aparelho respiratório & 38.962 & 30.845 & 28.729 & 98.536 & 17,83 \\
\hline 3- Doenças do aparelho digestivo & 21.500 & 22.356 & 30.113 & 73.969 & 13,39 \\
\hline 4- Igumas doenças infecciosas e parasitárias & 24.255 & 19.482 & 21.008 & 64.745 & 11,72 \\
\hline 5- Doenças do aparelho geniturinário & 12.505 & 10.935 & 13.227 & 36.667 & 06,63 \\
\hline 6- Transtornos mentais e comportamentais & 986 & 9.708 & 22.589 & 33.283 & 06,02 \\
\hline 7- Doenças sist osteomuscular e tec conjuntivo & 9.207 & 9.703 & 11.730 & 30.640 & 05,54 \\
\hline 8- Doenças do aparelho circulatório & 5.692 & 5.698 & 6.875 & 18.265 & 03,30 \\
\hline 9- Neoplasias (tumores) & 3.602 & 4.871 & 7.382 & 15.855 & 02,87 \\
\hline 10- Doenças do sistema nervoso & 5.401 & 5.580 & 4.766 & 15.747 & 02,85 \\
\hline 11- Doenças da pele e do tecido subcutâneo & 4.677 & 4.860 & 5.356 & 14.893 & 02,69 \\
\hline 12- Causas externas de morbidade e mortalidade & 3.981 & 4.701 & 5.537 & 14.219 & 02,57 \\
\hline Total & 167.669 & 173.431 & 211.252 & 552.352 & \\
\hline
\end{tabular}

Fonte: DATASUS/TABNET/MS

Morbidade Hospitalar do SUS - por local de residência - Brasil

Internações por Lista Morb CID-10 E Faixa Etária 2

Faixa Etária 2: 10 a 14 anos, 15 a 19 anos, 20 a 24 anos

\begin{tabular}{|l|c|c|c|r|r|}
\hline \multicolumn{1}{|c|}{ Lista Morb CID-10 } & 10 a 14 anos & 15 a 19 anos & 20 a 24 anos & Total & \% \\
\hline 1- Gravidez parto e puerpério & 36.565 & 706.552 & 915.086 & 1.658 .203 & $\mathbf{7 7 , 2 8}$ \\
\hline 2- Doenças do aparelho geniturinário & 10.756 & 38.495 & 57.003 & 106.254 & $\mathbf{4 , 9 5}$ \\
\hline 3- Doenças do aparelho respiratório & 34.963 & 32.882 & 32.262 & 100.107 & $\mathbf{4 , 6 6}$ \\
\hline 4- Doenças do aparelho digestivo & 13.966 & 23.243 & 36.615 & 73.824 & $\mathbf{3 , 4 4}$ \\
\hline 5- Algumas doenças infecciosas e parasitárias & 20.240 & 20.321 & 20.892 & 61.453 & $\mathbf{2 , 8 6}$ \\
\hline 6- Lesões enven e alg out conseq causas externas & 12.436 & 12.805 & 12.786 & 38.027 & $\mathbf{1 , 7 7}$ \\
\hline 7- Doenças do aparelho circulatório & 3.103 & 7.379 & 13.465 & 23.947 & $\mathbf{1 , 1 1}$ \\
\hline 8- Neoplasias (tumores) & 4.590 & 6.430 & 10.427 & 21.447 & $\mathbf{0 , 9 9}$ \\
\hline 9- Doenças sist osteomuscular e tec conjuntivo & 5.614 & 5.992 & 6758 & 18364 & $\mathbf{0 , 8 5}$ \\
\hline 10- Transtornos mentais e comportamentais & 748 & 4841 & 9658 & 15247 & $\mathbf{0 , 7 1}$ \\
\hline 11- Sint sinais e achad anorm ex clín e laborat & 2797 & 5316 & 7081 & 15194 & $\mathbf{0 , 7}$ \\
\hline 12- Doenças endócrinas nutricionais e metabólicas & 4169 & 4399 & 4962 & 13530 & $\mathbf{0 , 6 3}$ \\
\hline Total & $\mathbf{1 4 9 . 9 4 7}$ & $\mathbf{8 6 8 . 6 5 5}$ & $\mathbf{1 . 1 2 6 . 9 9 5}$ & $\mathbf{2 . 1 4 5 . 5 9 7}$ &
\end{tabular}

Sexo: Feminino/ 2001

Fonte: DATASUS/TABNET/MS 
As tabelas acima evidenciam que as causas de morbidade são bem diferenciadas por sexo. Verifica-se que a vulnerabilidade das mulheres nesta faixa etária está na saúde sexual e reprodutiva, enquanto que os homens estão mais expostos às causas de acidentes e violência.

O contingente masculino, de 10 a 24 anos de idade, tem como primeira causa de morbidade, dentro das primeiras doze causas, as lesões e envenenamentos e algumas outras causas externas, com uma incidência de 24,53\%; o percentual mais alto por faixa etária está na faixa de 20 - 24 anos de idade com $39,78 \%$, seguida pelos adolescentes de $15-19$ anos (32,97\%) e os de $10-14$ anos, com $37,22 \%$. Quando somadas a outras causas externas de morbidade e mortalidade, com o percentual de $2,35 \%$, mostram a vulnerabilidade dos homens adolescentes e jovens às questões relacionadas à violência.

\subsection{Alcoolismo: o maior problema de saúde pública}

O uso do álcool impõe às sociedades de todos os paises uma carga global de agravos indesejáveis e extremamente dispendiosos, que acometem os indivíduos em todas os domínios de sua vida. A reafirmação histórica do papel nocivo que o álcool nos oferece deu origem a uma gama extensa de respostas políticas para o enfrentamento dos problemas decorrentes de seu consumo, corroborando assim o fato concreto de que a magnitude da questão é enorme, no contexto de saúde pública mundial.

O diagnóstico e tratamento precoces da dependência ao álcool têm papel fundamental no prognóstico deste transtorno, o que se amplia em uma perspectiva global de prevenção e promoção da saúde, e se agrava ao constatarmos que, de uma forma geral, o despreparo significativo e a desinformação das pessoas que lidam diretamente com o problema, sejam elas usuários, familiares ou profissionais de saúde.

Aproximadamente $20 \%$ dos pacientes tratados na rede primária bebem em um nível considerado de alto risco, pelo menos fazendo uso abusivo do álcool. Estas pessoas têm seu primeiro contato com os serviços de saúde por intermédio de clínicos gerais. Apesar disso, estes pouco detectam a presença de acometimento por tal uso, o que tem repercussão negativa sobre as possibilidades de diagnostico e tratamento. Vemos que, no geral, o foco da atenção está voltado para as doenças clínicas decorrentes da dependência - que ocorrem tardiamente - e não para a dependência subjacente.

Os fatos acima assumem importância maior dentro de um contexto preventivo, ao considerarmos que, via de regra, o período médio entre o primeiro problema decorrente do uso de álcool e a primeira intervenção voltada para este problema é de 05 anos; a demora para iniciar o tratamento e a sua inadequação pioram o prognóstico. Dentre inúmeros fatores de influencia sobre a ineficácia da assistência disponível, consideramos sobremaneira a crença errônea de que os pacientes raramente se recuperam, sendo um fator decisivo para tanto a falta oferta de um currículo relativo a abordagem do uso 
de álcool e drogas que seja minimamente suficiente, pelas faculdades de medicina; ampliamos a questão para as instituições de ensino formadoras de outros profissionais de saúde, na desejável possibilidade de abordagens multiprofissionais para os consumidores.

Ainda de forma relativa aos profissionais de saúde, existem diversos impedimentos para a diagnosticar, tratar ou encaminhar as pessoas que apresentam complicações decorrentes do consumo de álcool. Em um plano cognitivo, os trabalhadores de saúde apresentam a falta de conhecimentos sobre a variedade de apresentações sintomáticas gerados pelo uso abusivo e pela dependência ao álcool, bem como de meios para facilitar o seu diagnostico. Apresentam também uma visão negativa do paciente, e de suas perspectivas evolutivas frente ao problema, o que impede uma atitude mais produtiva.

Devemos considerar que a não-compreensão fenomenológica da resistência freqüentemente apresentada pelos pacientes provoca nestes profissionais respostas pouco acolhedoras, o que se agrava na perspectiva de que a necessidade de acolhimento, enquanto estratégia facilitadora de abordagem, motivação, e aderência a qualquer proposta de cuidados, é fundamental. Tal acolhimento, em qualquer nível assistencial (especializado ou não-especializado), deve estar disponível no momento em que a sua necessidade se impõe, uma vez que a ambivalência, a flutuação motivacional e o imediatismo fazem parte da apresentação costumeiramente evidente naqueles que procuram os serviços de saúde, devido às conseqüências do seu consumo alcoólico. Podemos ainda apontar como impedimento o conceito normalmente abraçado pelos profissionais de saúde de que não possuem qualquer responsabilidade sobre o diagnostico e tratamento da dependência ao álcool, em uma evidente demonstração de estigma, exclusão e preconceito.

Ao analisarmos alguns dados correlatos e relativos aos custos decorrentes, vemos que os custos decorrentes do consumo de álcool são de grande magnitude. Considerando dados referentes ao ano de 2001 (DATASUS, 2001), tivemos no Brasil 84.467 internações para o tratamento de problemas relacionados ao uso do álcool, mais de quatro vezes o número de internações ocorridas por uso de outras drogas. No mesmo período, foram emitidas $121.901 \mathrm{AlHs}$ para as internações relacionadas ao alcoolismo. Como a média de permanência em internação foi de 27,3 dias para o período selecionado, estas internações tiveram em 2001 um custo anual para o SUS de mais de 60 milhões de reais.

Estes números não incluem os gastos com os tratamentos ambulatoriais, nem com as internações e outras formas de tratamento de doenças indiretamente provocadas pelo consumo do álcool, como aquelas que atingem os aparelhos digestivo e cardiovascular, câncer (principalmente hepático, de estômago e de mama), deficiências nutricionais, doenças do feto e recém nato da mãe alcoolista, as doenças neurológicas e o agravamento de outras doenças psiquiátricas provocado pelo álcool, assim como os agravos decorrentes de acidentes ou violência, o que se aplica a todos os povos. Pesquisa realizada pelo Instituto Nacional de Abuso de Álcool e Drogas dos EUA (1997) revelou que o uso excessivo de bebida estava presente em $68 \%$ dos homicídios culposos, $62 \%$ dos assaltos, $54 \%$ dos assassinato e $44 \%$ dos roubos ocorridos. De forma relativa à violência doméstica, a pesma pesquisa evidenciou que $2 / 3$ dos casos de espancamento de crianças ocorrem quando os pais agressores estão embriagados, o mesmo ocorrendo nas agressões entre marido e mulher. No Brasil, pesquisa realizada 
pelo CEBRID, 1996 informou que a análise de mais de 19.000 laudos cadavéricos feitos entre 1986 e 1993 no IML - de cada 100 corpos que deram entrada vítimas de morte não natural, 95 tinham álcool no sangue.

Ainda de acordo com o DATASUS, e considerando o período compreendido entre 1998 e 2001, verificamos que o maior percentual de gastos é decorrente do uso indevido de álcool - 87,9\%; contra $13 \%$ de gastos oriundos no consumo de outras substancias psicoativas.

TABELA I - MORBIDADE HOSPITALAR NO SUS - CAP V - TRANSTORNOS MENTAIS DECORRENTES DO USO DE ÁLCOOL E OUTRAS SUBSTÂNCIAS PSICOATIVAS - 1998 A 2001

\begin{tabular}{|c|c|c|}
\hline $\begin{array}{c}\text { Morbidades - CID-10 } \\
\text { 1998 a 2001 }\end{array}$ & Valor Total & $\begin{array}{c}\text { \% } \\
\text { Gastos }\end{array}$ \\
\hline $\begin{array}{c}\text { Transtornos mentais e } \\
\text { Comportamentais } \\
\text { decorrentes do uso de } \\
\text { álcool }\end{array}$ & 232.518 .454 & $87,9 \%$ \\
\hline $\begin{array}{c}\text { Transtornos mentais e } \\
\text { Comportamentais } \\
\text { decorrentes do uso de } \\
\text { outras substâncias } \\
\text { psicoativas }\end{array}$ & 31.830 .502 & $13,1 \%$ \\
\hline Total gastos anuais & 264.348 .956 & $100 \%$ \\
\hline & & \\
\hline & & \\
\hline
\end{tabular}

(Fonte: DATASUS, MS)

Os dados acima confirmam o consenso mundial de que as intervenções voltadas para minimizar os custos do gasto indevido de substâncias psicoativas devem dedicar atenção especial às drogas de uso lícito, especialmente o álcool. Poucos consumidores (os mais acometidos, em verdade) recebem atenção do sistema de saúde em dispositivos de atenção extra-hospitalar especializada (ainda pouco disponível) ou em nível de atenção básica; a atenção hospitalar no Brasil, componente de um modelo iatrogênico, ultrapassado e excludente de oferta de cuidados, não contempla as necessidades da maioria dos indivíduos que têm poucos problemas com o álcool, os quais constituem parcela maior da população de consumidores - portanto, com maior probabilidade e risco para desenvolver problemas mais graves, devendo ser alvo de intervenções preventivas, o que não deve ser absolutamente ignorado, dentro de uma perspectiva de saúde pública. Desta forma, prevenção precoce e intervenções breves podem ter efeitos benéficos que ultrapassam as suas populações-alvo. A oferta de cuidados extrahospitalares, inseridos na comunidade e complementados por outros programas assistenciais promove condições para a reversão deste panorama.

Repensar as formas de cuidar destas pessoas deve contemplar formas de intervenção precoce, dentro de uma perspectiva lógica de redução de danos, o que teria impacto altamente positivo sobre a carga global de problemas e sobre o custo direto e indireto associado ao consumo de álcool. 
Desta forma, uma política nacional de atenção à saúde, de forma relacionada ao consumo de álcool, implica na implementação da assistência, ampliando a cobertura e o espectro de atuação do Programa Nacional de Atenção Comunitária Integral a Usuários de Álcool e outras Drogas do Ministério da Saúde, o qual contempla a assistência a pessoas com problemas relacionados ao uso do álcool e seus familiares. A assistência a usuários de álcool deve ser oferecida em todos os níveis de atenção, privilegiando os cuidados em dispositivos extra-hospitalares, como os Centro de Atenção Psicossocial para Álcool e Drogas (CAPSad), devendo também estar inserida na atuação do Programa de Saúde da Família, programa de Agentes Comunitários de Saúde, e da Rede Básica de Saúde.

Também é fundamental aperfeiçoar a assistência dos casos de maior gravidade nos dispositivos de saúde que demandem por cuidados mais específicos em dispositivos de maior complexidade, como os serviços de emergências médicas (geral e emergência psiquiátrica), principalmente para o atendimento de urgências como os quadros de intoxicação ou abstinência graves e outros transtornos clínicos e psiquiátricos agudos; o mesmo deve ocorrer em hospitais psiquiátricos e hospitais gerais.

Quanto à capacitação, devem ser ampliadas as atividades do Programa Permanente de Capacitação de Recursos Humanos para os Serviços de Atenção aos Usuários de Drogas na Rede do SUS do Ministério da Saúde, capacitando não apenas os profissionais que atuarão nos CAPSad, como também os que atuam nas demais unidades assistenciais, atividade também extensiva ao PSF e PACS, contemplando também a capacitação para profissionais de nível médio que atuem na assistência aos problemas relacionados ao uso do álcool. É fundamental o desenvolvimento, em ação conjunta com o Ministério da Educação, a modificação do currículo dos cursos de graduação na área da saúde, exigindo a abordagem dos problemas relacionados ao uso do álcool.

Quanto ah prevenção, é essencial capacitar as equipes de saúde da família e prover os subsídios necessários para o desenvolvimento de ações de prevenção primária do uso prejudicial do álcool, para o diagnóstico precoce, tratamento de casos não complicados e referenciamento para a rede de assistência dos quadros moderados e graves.

Deve ser estimulado o desenvolvimento de ações de prevenção nas escolas, locais de trabalho, sindicatos e outras associações. As ações incentivadas devem ter caráter permanente, ao invés iniciativas pontuais e esporádicas como campanhas, sem no entanto, prescindir de ações de curta duração voltadas para a multiplicação da atuação preventiva.

Educar a população é fundamental, pois promove a redução dos obstáculos relativos ao ao tratamento e à atenção integral voltada para os consumidores de álcool, aumentando a consciência coletiva sobre a freqüência dos transtornos decorrentes do uso indevido de álcool e drogas. As opções de atenção disponíveis e seus benefícios devem ser amplamente divulgados.

As respostas da população em geral, dos profissionais, da mídia, dos formuladores de políticas e dos políticos devem refletir os melhores conhecimentos disponíveis. Campanhas de educação e 
sensibilização, caso bem organizadas, reduzem a discriminação e a estigmatização, e fomentam o uso dos serviços disponíveis. Desta forma, as atividade preventivas também devem ser orientadas ao fornecimento de informações e discussão dos problemas provocados pelo consumo do álcool, sempre tendo em mente a estratégia de redução de danos, tendo ainda como fundamento uma visão compreensiva do consumo do álcool como fenômeno social, e ao mesmo tempo individual.

Quanto à mídia, uma política para redução de danos relacionados ao consumo de álcool deve necessariamente propor modificação na legislação na direção da proibição da propaganda de bebidas alcoólicas em meios de comunicação de massa. A propaganda deve ficar restrita aos locais de venda (bares, prateleiras de supermercado, etc), como já é feito no Brasil para o tabaco. Os veículos de comunicação de massa devem ser incentivados a realizar campanhas de redução dos danos à saúde provocados pelo consumo do álcool. O eixo norteador de campanhas pela redução dos problemas provocados pelo álcool deve ser a estratégia de redução de danos, devendo haver a crítica de estereótipos relacionados ao uso do álcool, e incentivados pela propaganda de bebidas alcoólicas, como a associação do uso do álcool com a virilidade, a sensualidade, diversão etc. Produtores, distribuidores e estabelecimentos que vendem bebidas devem ser implicados no desenvolvimento da campanha de prevenção, através de suas associações.

Quanto ao controle social dos danos à saúde relacionados ao uso do álcool, deve ser fomentado o debate público em várias instâncias de modo a viabilizar o controle social sobre os danos à saúde e relacionados ao consumo de bebidas alcoólicas. Este debate deve abordar medidas como a Revisão da taxação de bebidas alcoólicas através de imposto que seria destinado ao custeio da assistência e prevenção dos problemas relacionados ao uso do álcool, bem como pela discussão, implantação e implementação das propostas constantes no Relatório Final da III Conferência Nacional de Saúde Mental (III CNSM, 2001).

As discussões sobre o controle social e político do álcool devem combater argumentos mais liberais, os quais preconizam que a oferta e a demanda do álcool deveria ser algo que o próprio mercado deveria regular; que no Brasil temos controle em demasia, e que não necessitaríamos de mais um controle sobre esse produto, sendo também pouco democrático fazermos controle de um produto que é legalizado.

Para tanto, deve utilizar fortes contra-argumentos, no sentido de que são exatamente os países mais desenvolvidos do ponto de vista democrático que aumentam a cada dia o controle social sobre o álcool. É necessário privilegiar o interesse da sociedade em proteger-se dos danos causados pelo álcool, face ao interesse da industria de bebidas, sendo portanto imperativo um exercício menos tímido e mais eficaz do controle social, no sentido de implementação das propostas que configurem uma política pública relativa ao uso de álcool. 


\subsection{Uso de Drogas e Início da Vida Sexual}

Estudos demográficos apontam para crescente tendência de redução da faixa etária de início de vida sexual (em torno de 13 anos), refletida em altos índices de gravidez na adolescência, o que coincide com um início igualmente precoce do uso de bebidas alcoólicas. Pesquisa realizada na periferia de Caruaru (PE) confirmou esses dados, ao revelar que $27,6 \%$ dos entrevistados tiveram a primeira relação sexual antes dos 13 anos, e 80,1\% tiveram antes dos 17 anos. Tais índices coincidem com a idade média de início de consumo de bebidas alcoólicas, também extraídos da pesquisa supracitada: $32,2 \%$ começaram a beber antes dos 13 anos e $74,9 \%$ antes dos 17 anos.

Os dados preliminares da última pesquisa realizada pelo Centro Brasileiro de Informações sobre Drogas Psicotrópicas (CEBRID) - UNIFESP: "Relação ente o uso de Crack e o desenvolvimento de comportamento de risco para a infecção de DST/HIV/AIDS”, com 150 mulheres usuárias de crack de São Paulo e São José do Rio Preto, demonstram que $80 \%$ das entrevistadas referem que a idade da primeira experiência sexual ocorreu antes dos 15 anos de idade, sendo que metade da amostra teve sua iniciação antes dos 14 anos. Constata-se o dado alarmante de $17 \%$ da iniciação sexual por estupro. Das entrevistadas, $72 \%$ referiu não saber que teria que se proteger nas relações sexuais, revelando baixo conhecimento sobre doenças sexualmente transmissíveis; conseqüentemente, o percentual dessas mulheres que refere ter usado preservativo na primeira relação sexual é extremamente baixo: $7 \%$. Essas mulheres iniciaram precocemente o uso de crack, geralmente por influência do companheiro, sendo que para algumas o crack foi a primeira droga psicotrópica utilizada. Citam o álcool e a maconha como substâncias de uso obrigatoriamente associado ao crack.

\subsection{Meninos e Meninas de Rua e o Consumo de Drogas}

Outro estudo atual e relevante foi realizado pelo MS em parceria com o Movimento Nacional de Meninos e Meninas de Rua - MNMMR no mês de Junho/2002, junto a crianças e adolescentes em situação de risco social. A amostra foi composta de 632 crianças e adolescentes entre 10 e 23 anos. Destacamos alguns dados gerais:

- $53,5 \%$ são do sexo masculino, e $46,5 \%$ do sexo feminino;

- $85 \%$ dos entrevistados encontram-se na faixa etária de 13 a 17 anos;

- $94,8 \%$ referem freqüentar a escola regularmente;

- $89,5 \%$ referem morar na maioria dos dias da semana com a família, apenas $0,1 \%$ mora nas ruas e $9,5 \%$ em instituições.

Quanto aos conhecimentos sobre formas de contágio de AIDS, a pesquisa mostrou que 93,2\% dessa população jovem tem informação sobre a infecção através do compartilhamento de seringas. Quanto ao 
uso de drogas, 23,2\% refere já ter usado algum tipo de droga e quanto ao uso de droga por via injetável compartilhando a mesma seringa ou agulhas há referência em $0,8 \%$ da amostra.

Quando questionados sobre as drogas mais utilizadas pelas pessoas nos locais onde moram (perguntas com múltiplas escolhas), relataram:

* Álcool: $66,7 \%$

* Maconha: $65,1 \%$

* Cola: $41,7 \%$

* Cocaína: $19,6 \%$

* Crack: $13,13 \%$

- Droga Injetável: 6,5\%

\subsection{A Epidemia de AIDS e a Rota do Tráfico}

Defrontamo-nos com um cenário complexo e em permanente mutação referente tanto ao tráfico quanto ao consumo de drogas (vide mapa com descrição de rota de tráfico de drogas). Este cenário repercute de forma importante na dinâmica da epidemia do HIV/AIDS, reclamando diversas alternativas preventivas, aplicáveis a contextos que variam de regiões com um uso incipiente de drogas injetáveis (ainda que de um consumo intenso de drogas ilícitas pelas demais vias) a regiões onde existem epidemias maduras de HIV/AIDS na população local de UDI (com taxas de infecção pelo HIV por vezes superiores a $60 \%)$.

\subsection{Uso de Drogas Injetáveis}

O uso compartilhado de equipamentos utilizados na auto-administração de drogas injetáveis - com o predomínio da cocaína injetável, é direta ou indiretamente, responsável por cerca de $25 \%$ do total de casos de AIDS notificados. Além da infecção pelo HIV, as demais doenças de transmissão sangüínea são bastante prevalentes entre os usuários de drogas injetáveis (UDI) brasileiros, com taxas elevadas de infecção pelos agentes etiológicos das hepatites virais, além de infecções particularmente comuns em determinadas regiões brasileiras, como a infecção pelo HTLV I / II, endêmica na Bahia e região nordeste do Brasil, alem de surtos de malária transmitidos por equipamentos de injeção.

Embora ainda não tenhamos dados consistentes, pesquisas pontuais e a observação da realidade demonstram crescimento do compartilhamento de seringas e agulhas para uso de anabolizantes em academias e de silicone injetável entre travestis. Por ora, estima-se, a partir de dados disponibilizados 
por diferentes pesquisas, que existam cerca de 800.000 usuários de drogas injetáveis (UDI) no país, com utilização desta via de consumo ao menos uma vez nos últimos 12 meses, com as seguintes características:

- São jovens, entre 18 a 30 anos, tendo iniciado o consumo de drogas injetável por volta dos 16 anos;

- A escolaridade é baixa, tendo a maioria o primeiro grau incompleto;

- A média de injeção gira em torno de 10 a 25 vezes por sessão de uso;

- Altas taxas de HIV = 36,5\%, Hepatite C = 56,4 \%;

- $85 \%$ dos UDI relatam o uso de droga em grupo;

- $23 \%$ procuraram tratamento para a dependência química em algum momento da vida;

- $80 \%$ já foram presos pelo menos uma vez; 


\section{DIRETRIZES PARA UMA POLÍTICA DE ATENÇÃO INTEGRAL AOS USUÁRIOS DE ÁLCOOL E OUTRAS DROGAS}

As políticas e práticas dirigidas para pessoas que apresentam problemas decorrentes do uso de álcool e outras drogas, no âmbito de atuação do Ministério da Saúde, devem estar obrigatoriamente integradas às propostas elaboradas pela Área Técnica de Saúde Mental / Álcool e Drogas do MS.

As diretrizes para uma política ministerial específica para a atenção a estes indivíduos estão em consonância com os princípios da política de saúde mental vigente - preconizada, articulada e implementada pelo Ministério da Saúde; uma vez regulamentada e respaldada pela Lei Federal 10.216 (MS, 2002), sancionada em 6/4/2001, constitui a política de Saúde Mental oficial para o Ministério da Saúde, bem como para todas as unidades federativas.

Assim sendo, a Lei Federal 10.216 (MS, 2002) também vem a ser o instrumento legal / normativo máximo para a política de atenção aos usuários de álcool e outras drogas, a qual também se encontra em sintonia para com as propostas e pressupostos da Organização Mundial da Saúde. A Lei em questão tem diversos desdobramentos positivos possíveis, se aplicada com eficácia (Delgado, 2002)

Viabilizando as deliberações da III Conferencia Nacional de Saúde Mental, no sentido de normalizar a atenção a usuários de álcool e drogas, o Ministério da Saúde publicou portarias voltadas para a estruturação de rede de atenção especifica a estas pessoas. A Portaria GM / 336 de 19 de fevereiro de 2002 (MS, 2002) define normas e diretrizes para a organização de serviços que prestam assistência em saúde mental, tipo "Centros de Atenção Psicossocial - CAPS"- incluídos aqui os CAPS voltados para o atendimento aos usuários de álcool e drogas, os CAPSad. Já a Portaria SAS / 189 de 20 de março de 2002 (MS, 2002) regulamenta a Portaria GM / 336, criando no âmbito do SUS os "serviços de atenção psicossocial para o desenvolvimento de atividades em saúde mental para pacientes com transtornos decorrentes do uso prejudicial e/ou dependência de álcool e outras drogas".

A necessidade de definição de estratégias específicas de enfrentamento que visam ao fortalecimento da rede de assistência aos usuários de álcool e outras drogas, com ênfase na reabilitação e reinserção social dos mesmos levou o Ministério da Saúde a instituir, no âmbito do Sistema Único de Saúde, o Programa Nacional de Atenção Comunitária Integrada aos Usuários de Álcool e Outras Drogas, via Portaria GM / 816 de 30 de abril de 2002 (MS, 2002); mediante a consideração da multiplicidade de níveis de organização das redes assistenciais localizadas nos Estados e Distrito Federal, da diversidade das características populacionais existentes no País, e da variação da incidência de transtornos causados pelo uso abusivo e/ou dependência de álcool e outras drogas, o Ministério da Saúde propõe a criação de 250 Centros de Atenção Psicossocial - CAPSad, dispositivo assistencial de comprovada resolubilidade, podendo abrigar em seus projetos terapêuticos práticas de cuidados que contemplem a flexibilidade e abrangência possíveis e necessárias a esta atenção específica, dentro de uma perspectiva estratégica de redução de danos sociais e à saúde. 
O programa considera ainda a necessidade de estruturação e fortalecimento de uma rede de assistência centrada na atenção comunitária associada à rede de serviços de saúde e sociais, que tenha ênfase na reabilitação e reinserção social dos seus usuários; considera ainda que a atenção psicossocial a pacientes com dependência e/ou uso prejudicial de álcool e outras drogas deve se basear em uma rede de dispositivos comunitários, integrados ao meio cultural, e articulados à rede assistencial em saúde mental e aos princípios da Reforma Psiquiátrica.

Estes dispositivos, os já mencionados CAPSad, devem oferecer atendimento diário, sendo capazes de oferecer atendimento nas modalidades intensiva, semi-intensiva e não-intensiva, permitindo o planejamento terapêutico dentro de uma perspectiva individualizada de evolução contínua. Possibilitam ainda intervenções precoces, limitando o estigma associado ao tratamento. Assim, a rede proposta se baseia nestes serviços comunitários, apoiados por leitos psiquiátricos em hospital geral e outras práticas de atenção comunitária (ex.: internação domiciliar, participação comunitária na discussão dos serviços), de acordo com as necessidades da população-alvo dos trabalhos.

No que se refere às estratégias necessárias para a reformulação da Política Nacional de Álcool e Drogas, é relevante destacar algumas características do campo de práticas, observadas no cenário nacional e internacional:

1. o consumo de drogas não atinge de maneira uniforme toda a população e sua distribuição é distinta nas diferentes regiões do país, apresentando inclusive diferenças significativas em uma mesma região, tanto nos aspectos sociais quanto nas vias de utilização e na escolha do produto;

2. a pauperização do país, que atinge em maior número pessoas, famílias ou jovens de comunidades já empobrecidas, apresenta o tráfico como possibilidade de geração de renda e medida de proteção;

3. o aumento no início precoce em uso de drogas legais entre os jovens e utilização cada vez mais freqüente de uso de drogas de design e crack, e o seu impacto nas condições de saúde física e psíquica dos jovens, notadamente pela infecção ao HIV e hepatites virais;

4. a definição de políticas internacionais que contextualizam os países em desenvolvimento somente a partir de sua condição de produção, refino e exportação de produtos nocivos à saúde.

Por outro lado, a insuficiência/ausência histórica de políticas que promovam a promoção e proteção social, de saúde e tratamento das pessoas que usam, abusam ou são dependentes de álcool são determinantes para o aumento de suas vulnerabilidades.

Somado a esses fatores, o rigor da Lei Criminal de drogas vigente manifesta-se em condições desfavoráveis de acesso à saúde e a participação e organização dos usuários de drogas, ao estabelecer o uso como "proibido", sugerindo a ocultação. Além disso, ao dividir-se as drogas em lícitas e ilícitas, 
incorre-se na concentração de perigo e pânico diante daquelas substâncias qualificadas de ilícitas, havendo inclusive incentivo àquelas qualificadas de lícitas.

Ressaltamos a necessidade de desenvolver ações de atenção integral ao uso de álcool e drogas nas grandes cidades de forma diferenciada, devido à constatação de que, nas periferias, locais de concentração dos denominados "cinturões de pobreza", há subsistemas sociais que incluem grupos organizados (de drogas, crime, gangues etc.), além de ausência de fatores de proteção à comunidade que direta e/ou indiretamente possam contribuir para a diminuição das vulnerabilidades da população, como por exemplo implementação de iluminação pública, saneamento, centros sociais e de lazer, jornadas duplas de escolaridade para jovens com atividades sócio-educacionais, profissionalizantes e recreativas etc.

Principais fatores que reforçam a exclusão social dos usuários de drogas:

1. Associação do uso de álcool e drogas à delinqüência, sem critérios mínimos de avaliação

2. O estigma atribuído aos usuários, promovendo a sua segregação social

3. Inclusão do tráfico como uma alternativa de trabalho e geração de renda para as populações mais empobrecidas, em especial à utilização de mão de obra de jovens neste mercado

4. A ilicitude do uso impede a participação social de forma organizada desses usuários

5. O tratamento legal e de forma igualitária a todos os integrantes da "cadeia organizacional do mundo das drogas" é desigual em termos de penalização e alternativas de intervenção

Desta forma, todas as propostas abaixo descritas têm o objetivo imprescindível de:

1) alocar a questão do uso de álcool e outras drogas como problema de saúde pública,

2) Indicar o paradigma da redução de danos - estratégia de saúde pública que visa reduzir os danos causados pelo abuso de drogas lícitas e ilícitas, resgatando o usuário em seu papel autoregulador, sem a preconização imediata da abstinência e incentivando-o à mobilização social - nas ações de prevenção e de tratamento, como um método clínico-político de ação territorial inserido na perspectiva da clínica ampliada;

3) Formular políticas que possam desconstruir o senso comum de que todo usuário de droga é um doente que requer internação, prisão ou absolvição;

4) Mobilizar a sociedade civil, oferecendo à mesma condições de exercer seu controle, participar das práticas preventivas, terapêuticas e reabilitadoras, bem como estabelecer parcerias locais para o fortalecimento das políticas municipais e estaduais. 


\section{1. - Intersetorialidade}

O impacto de políticas públicas coordenadas setorialmente é visível, e vem se impondo para todas as áreas sociais de governo. $O$ desafio colocado é o de aperfeiçoar os instrumentos de acompanhamento e de geração de informações, que tornem factíveis os processos de avaliação e de gestão dos programas.

O uso de álcool e outras drogas, por tratar-se de um tema transversal a outras áreas da saúde, da justiça, da educação, social e de desenvolvimento, requer uma intensa capilaridade para a execução de uma política de atenção integral ao consumidor de álcool e outras drogas.

As articulações com a sociedade civil, movimentos sindicais, associações e organizações comunitárias e universidades, são fundamentais para a elaboração de planos estratégicos dos estados e municípios, ampliando-se significativamente a cobertura das ações dirigidas a populações de difícil acesso. Tais articulações constituem-se em instrumentos fundamentais de defesa e promoção de direitos (advocacy) e de controle social.

Nesse sentido, no campo da prática de políticas públicas, a intersetorialidade e a intrasetorialidade requerem investimentos contínuos e de longo prazo, dedicando esforços coerentes a cada nova geração. A integralidade das ações, com a conseqüente definição de papéis entre os diversos níveis de governabilidade requer:

1. construção de oportunidades de inserção das ações nos mecanismos implementados pelo Sistema Único de Saúde (SUS) nestas esferas de governo;

2. a formulação de alternativas de sustentabilidade e de financiamento das ações;

3. o repasse das experiências relativas às iniciativas de descentralização e da desconcentração de atividades e de responsabilidades obtidas por estados e municípios;

4. processos de formação e capacitação de profissionais e de trabalhadores de saúde, com amplo investimento político e operacional para a mudança de conceitos.

As ações de cooperação internacional também fortalecem este processo de articulação e de gestão, à medida em que promovem a negociação de projetos e atividades de cooperação, a sua formalização junto às instâncias pertinentes, e as providências técnico-administrativas para viabilização destas ações, bem como a articulação com organismos internacionais e com governos estrangeiros, no sentido de desenvolver ações de cooperação técnica, científica, tecnológica e financeira.

Uma das propostas que se vislumbra como geradora de conhecimento e informação é a interação sistemática entre as universidades, centros de pesquisa e o envolvimento de diversos serviços de saúde, educação e sociais na constituição de sistemas locais de inovação científica e tecnológica aplicada aos 
problemas derivados do uso de drogas, bem como a articulação com outros setores sociais nacionais e internacionais comprometidos com a produção de conhecimentos neste campo.

\section{2 - Atenção Integral}

Definir políticas públicas para a promoção de mudanças capazes de manterem-se estáveis nos diferentes níveis envolvidos, requer:

1. mudanças individuais de comportamento que estão diretamente vinculadas a estratégias globais de diminuição de riscos individuais e nos grupos de pares;

2. a mudança de crenças e normas sociais;

3. ações de informação e prevenção, destinadas à população em geral com vistas a participação comunitária;

4. diversificação e ampliação da oferta de serviços assistenciais;

5. adoção de políticas de promoção a saúde que contemplem ações estruturais nas áreas de educação, saúde e de acesso a bens e serviços - em suma, que incluam na agenda a questão do desenvolvimento;

6. discussão das leis criminais de drogas e implementação de dispositivos legais para a eqüidade do acesso dos usuários de álcool e drogas às ações de prevenção, tratamento e redução de danos, de acordo com prioridades locais e grau de vulnerabilidade;

7. revisão da lei que permite demissão por justa causa em empresas que constatam o uso de drogas por funcionários

8. discussão e impedimento de testagem de uso de drogas, realizados de forma compulsória em funcionários de empresas e estudantes de escolas públicas.

O estabelecimento de uma política exitosa deve prever sua descentralização e autonomia de gestão pelos níveis estaduais e municipais. Para tanto, a definição dos papéis de cada nível é fundamental, assim como a definição dos mecanismos de captação, utilização e repasse de recursos financeiros pelos três níveis de governo, de forma a equalizar os gastos em vigilância, tratamento, prevenção, redução de danos e repressão.

Para tanto, é fundamental a recomposição das instâncias estaduais e municipais de controle da política de drogas, juntamente aos conselhos de saúde, ressaltando-se o ganho incomensurável se tais instâncias promoverem a participação de consumidores de drogas para a formulação de políticas locais. Os conselhos de saúde necessitam resgatar seu papel articulador entre os diferentes segmentos e não se constituírem em executores de ações. É Importante ressaltar que a implementação de um sistema de formação de recursos humanos especificamente voltado para este tema é imprescindível. 
Para a questão especifica do consumo de drogas, o mundo defronta-se com o desafio de encontrar respostas que possam trazer, em médio prazo, a melhoria substancial das condições de vida das pessoas consumidoras de drogas, bem como respostas potentes relativas à prevenção e tratamento.

Os principais limites observados pela falta de prioridade dada a uma política de saúde integral dirigida ao consumidor de álcool e outras drogas pode ser observada a partir do impacto econômico e social que tem recaído para o SUS, seja por seus custos diretos, seja pela impossibilidade de resposta de outras pastas governamentais, de forma a impactar positivamente na redução do consumo de drogas, no resgate do usuário do ponto de vista da saúde e não tão somente moralista ou legalista, e em estratégias de comunicação que reforçam o senso comum de que todo consumidor é marginal e perigoso para a sociedade.

\subsection{1 - Prevenção}

Em todo o mundo, são evidentes os agravos decorrentes do uso indevido de substâncias psicoativas; também é de conhecimento público a crescente elevação dos custos decorrentes direta ou indiretamente de tal uso. O estigma, a exclusão, o preconceito, a discriminação e a desabilitação são ao mesmo tempo agravantes e conseqüências do uso indevido de álcool e drogas, colaborando morbidamente para a situação de comprometimento global que acomete tais pessoas. Isto também ocorre relativamente aos outros transtornos mentais.

Em uma evidência constante no tempo, a elevação do consumo evolui de maneira proporcional ao crescimento da problemática psicossocial correlata, devidamente manifesta em todos os segmentos sociais; por sua vez, estes têm contribuído historicamente para o reforço negativo dos agravantes acima citados, fato amplamente comprovado ao analisarmos o despreparo global de todos (profissionais de saúde, pacientes e familiares, no geral) os envolvidos com questões decorrentes de tal uso (Crisp, 2000).

Devemos ainda considerar o caráter informativo alarmista em relação ao real status quo do problema; tabaco e álcool, substâncias de uso historicamente lícito e as mais consumidas em todo o mundo, são também as que trazem maiores e mais graves conseqüências para a saúde pública mundial. Com a mesma magnitude, deve ser levada em conta a grande timidez nacional em propor práticas de efetivo controle social relativo à comercialização destes produtos, que não trouxessem inevitavelmente a consolidação de uma cultura de falsos constrangimentos, e que fossem facilitadoras para a redução de danos e custos decorrentes do seu uso indevido.

O comprometimento global conseqüente ao uso de álcool e outras drogas envolve muito estigma, exclusão e preconceito. Além disso, sofre influência da desabilitação que promove, sendo esta definida 
como a perda ou restrição nas habilidades de um indivíduo para exercer uma atividade, função ou papel social, em qualquer um dos domínios da vida de relação. Suas conseqüências afetam, com considerável prejuízo, as nações do mundo inteiro, ultrapassando fronteiras, na medida em que a problemática inerente ao abuso e/ou dependência de drogas avança por todas as sociedades, envolvendo homens e mulheres de diferentes grupos étnicos, independentemente de classe social e econômica, ou mesmo de idade.

A prevenção voltada para o uso abusivo e/ou dependência de álcool e outras drogas pode ser definida como um processo de planejamento, implantação e implementação de múltiplas estratégias voltadas para a redução dos fatores de vulnerabilidade e risco específicos, e fortalecimento dos fatores de proteção. Implica necessariamente em inserção comunitária das práticas propostas, com a colaboração de todos os segmentos sociais disponíveis, buscando atuar, dentro de suas competências, para facilitar processos que levem à redução da iniciação no consumo, do aumento deste em freqüência e intensidade, e das consequências do uso em padrões de maior acometimento global. Para tanto, a lógica da redução de danos deve ser considerada como estratégica ao planejamento de propostas e ações preventivas.

O compartilhamento de responsabilidades, de forma orientada às praticas de efeito preventivo, também não deve abrir mão da participação dos indivíduos diretamente envolvidos com o uso de álcool e outras drogas, na medida em que devem ser implicados como responsáveis por suas próprias escolhas, e como agentes e receptores de influências ambientais (Marlatt, 1999). Também não deve dispensar a participação dos que não estão diretamente envolvidos, ao contrário: as intervenções de cunho preventivo devem ser aplicáveis para toda a população, considerando que a maior parcela da mesma ainda não foi atingida pelo problema em questão, e que um grande contingente de indivíduos se encontra em grupos de baixo/moderado risco para o uso abusivo e/ou dependência de álcool e outras drogas. Isto ratifica a consideração estratégica da redução de danos, uma vez que possibilita um planejamento mais flexível e abrangente de atividades preventivas, dentro de um contexto de saúde publica.

Devemos ainda considerar o enorme contingente de crianças e adolescentes, no Brasil. Levando em conta que a sociedade deve assumir o compromisso ético de cuidar de suas crianças e adolescentes, isto deveria encontrar equivalência no aumento na atenção global voltada para esta faixa etária específica; não devemos esquecer que o descaso do presente poderá incorrer em um custo futuro pesado para toda a sociedade.

Cada indivíduo constitui campo de integração e inter-relação de vários fenômenos de manifestação biopsicossocial, sendo ainda o local de entrecruzamento para estas variáveis. A maneira como este indivíduo percebe conscientemente esta interseção pode ser definida como subjetividade, sendo esta o sítio de percepção e manifestação do que lhe é relativo, inclusive no tocante à sua própria saúde. Ao considerarmos que a promoção de saúde encontra seu espaço na busca constante de mais qualidade de vida para as pessoas, e que o mesmo deve acontecer em relação aos que são alvo das ações de prevenção, temos que qualquer tentativa de reduzir ou eliminar uma possível influência de fatores sobre 
a vulnerabilidade e o risco para o uso abusivo e/ou dependência de álcool e drogas deve considerar as práticas de vida diária destes indivíduos. Vale a pena ratificar que, se estas práticas podem influenciar positiva ou negativamente o seu bem estar, podem ser qualificadas como fatores de proteção ou de risco para este uso indevido.

Os fatores de risco para o uso de álcool e outras drogas são características ou atributos de um indivíduo, grupo ou ambiente de convívio social, que contribuem para aumentar a probabilidade da ocorrência deste uso. Por sua vez, se tal consumo ocorre na comunidade, é no âmbito comunitário que terão lugar as práticas preventivas de maior impacto sobre a vulnerabilidade e o risco.

Fatores de risco e de proteção podem ser identificados em todos os domínios da vida: nos próprios indivíduos, em suas famílias, em seus pares, em suas escolas e nas comunidades, e em qualquer outro nível de convivência sócio-ambiental. É importante notar que tais fatores não se apresentam de forma estanque, havendo entre eles considerável transversalidade, e conseqüente variabilidade de influência. Ainda assim, podemos dizer que a vulnerabilidade é maior em indivíduos que estão insatisfeitos com a sua qualidade de vida, possuem saúde deficiente, não detêm informações minimamente adequadas sobre a questão de álcool e drogas, possuem fácil acesso às substâncias e integração comunitária deficiente.

Assim como podemos identificar os fatores de risco atuantes em cada um dos domínios citados, podemos fazer o mesmo para os fatores específicos de proteção. Vejamos:

- No domínio individual, podemos identificar como principais fatores de risco a baixa auto-estima, falta de auto-controle e assertividade, comportamento anti-social precoce, doenças pré-existentes (ex.: transtorno de déficit de atenção e hiperatividade), e vulnerabilidade psicossocial. Como fatores de proteção, a apresentação de habilidades sociais, flexibilidade, habilidade em resolver problemas, facilidade de cooperar, autonomia, responsabilidade e comunicabilidade são os mais influentes, paralelamente à vinculação familiar-afetiva ou institucional.

- Quanto à família, vemos que o uso de álcool e outras drogas pelos pais é um fator de risco importante, assim como a ocorrência de isolamento social entre os membros da família. Também é negativamente influente um padrão familiar disfuncional, bem como a falta do elemento paterno. São considerados fatores de proteção a existência de vinculação familiar, com o desenvolvimento de valores e o compartilhamento de tarefas no lar, bem como a troca de informações entre os membros da família sobre as suas rotinas e práticas diárias; o cultivo de valores familiares, regras e rotinas domésticas também deve ser considerado, e viabilizado através da intensificação do contato entre os componentes de cada núcleo familiar.

- No domínio das relações interpessoais, os principais fatores de risco são pares que usam drogas, ou ainda que aprovam e/ou valorizam o seu uso; a rejeição sistemática de regras, práticas ou atividades 
organizadas também é aqui considerada como um sinalizador. Ao contrário, pares que não usam álcool / drogas, e não aprovam ou valorizam o seu uso exercem influência positiva, o mesmo ocorrendo com aqueles envolvidos com atividades de qualquer ordem (recreativa, escolar, profissional, religiosa ou outras), que não envolvam o uso indevido de álcool e outras drogas.

- Nos ambientes de formação e aprendizado, ocorre o entrecruzamento de fatores de risco presentes em todos os outros domínios; em verdade, a escola é o ambiente em que boa parte (ou a maioria) destes fatores pode ser percebida. De qualquer forma, os maiores fatores de risco apresentados são a falta de habilidade de convivência com grupos e a disponibilidade de álcool e drogas na escola e nas redondezas; além disso, uma escola que apresente regras e papéis inconsistentes ou ambíguos com relação ao uso de drogas ou à conduta dos estudantes também vem por constituir importante fator de risco relativo ao uso de álcool e drogas. Apresenta fatores de proteção o ambiente de ensino que evidencia regras claras e consistentes sobre a conduta considerada adequada - desde que isto faça parte de um processo educativo e evolutivo docente-assistencial que considere cada vez mais a participação dos estudantes em decisões sobre questões escolares, com a inerente e progressiva aquisição de responsabilidades.

O planejamento de ações preventivas e relativas ao uso de álcool e drogas deve obrigatoriamente considerar a mudança de relação na proporção de ocorrência entre buscar minimizar a influencia de fatores de risco sobre a vulnerabilidade dos indivíduos para tal uso; sinergicamente, também deve considerar o reforço dos fatores de proteção. Neste ponto, é fundamental perceber a importância da educação em saúde como estratégia fundamental para a prevenção.

O Relatório Mundial da Saúde - Saúde Mental: Nova Concepção, Nova Esperança (OMS, 2001) traz dez recomendações básicas para ações na área de saúde mental / álcool e drogas. São elas:

1. Promover assistência em nível de cuidados primários

2. Disponibilizar medicamentos de uso essencial em saúde mental

3. Promover cuidados comunitários

4. Educar a população

5. Envolver comunidades, famílias e usuários

6. Estabelecer políticas, programas e legislação específica

7. Desenvolver recursos humanos

8. Atuar de forma integrada com outros setores

9. Monitorizar a saúde mental da comunidade

10. Apoiar mais pesquisas

A grande relação entre a educação e as práticas preventivas e assistenciais fica explicita nestas recomendações, seja de forma direta, seja por intermédio de seus possíveis resultados e desdobramentos. Vale a pena lembrar que a separação entre prevenção e assistência não apresenta consistência teórica e/ou prática, no campo da saúde pública. Uma concepção integral e equânime de saúde não pretere prevenção em função de assistência, ou vice-e-versa. Assim sendo, pràticas 
preventivas voltadas para a educação em álcool e drogas devem ser planejadas levando em conta a especificidade inerente a cada parcela populacional, sempre de forma articulada a outras ações voltadas para a prevenção e promoção de atenção integral à saúde.

Repassar informações sobre os efeitos e conseqüências do uso de álcool e drogas é útil, porem de validade questionável, quando feito de forma isolada e desconectada de um programa de prevenção desenhado de forma a respeitar as características de sua população-alvo. Vemos ainda que a percepção distorcida da realidade do uso de substâncias psicoativas promove a disseminação de uma cultura de combate às drogas, substâncias inertes por natureza, fazendo com que o indivíduo e o seu meio de convívio fiquem aparentemente relegados a um plano menos importante. Isto por vezes é confirmado pela multiplicidade de propostas e abordagens preventivas/terapêuticas consideravelmente ineficazes, por vezes reforçadoras da própria situação de uso indevido e dependência.

Os fatos acima ratificam a necessidade imperiosa de capacitação e formação, de forma orientada aos profissionais de saúde, em uma perspectiva multiprofissional. Devem ser planejadas ações de capacitação voltadas para os trabalhadores de saúde componentes de equipes atuantes em unidades especializadas tipo CAPSad, uma vez que, estrategicamente, tais unidades também possuem a atribuição de multiplicar conhecimentos para equipes atuantes na atenção básica. Da mesma forma, ao pensarmos em estruturação de redes assistenciais locais, devemos contemplar também (e preferencialmente, de forma simultânea) outras unidades componentes, como unidades básicas de saúde e hospitais que mantenham leitos para internações de curta duração, assim como profissionais atuantes no Programa de Saúde da Família e Programa de Agentes Comunitários de Saúde, bem como para aqueles que trabalham de forma similar, porém voltada para a saúde indígena. De acordo com o planejamento estratégico dos gestores para a reconfiguração de suas redes locais de cuidados, contemplar profissionais atuantes em estruturas hospitalares que obedecem ao modelo hospitalocêntrico pode ser útil, no sentido de facilitar a mudança cultural e paradigmática necessária ao processo de reversão modelar assistencial.

A capacitação destes diversos profissionais deve considerar a sua formação e atuação, contemplando as intervenções possíveis em cada nível assistencial. Sempre devemos considerar o potencial informativo que detêm junto aos usuários dos serviços de saúde e suas famílias, o mesmo ocorrendo em relação às suas comunidades, de forma geral.

Dentro desta perspectiva de atuação estratégica, o Ministério da Saúde implantou em 2002 o Programa de Formação e Capacitação de Recursos Humanos Voltados para a Atenção aos Usuários de Álcool e Drogas na rede SUS, com a realização de cursos nos formatos de especialização, atualização e informacao técnica, pensados para ocorrer de forma norteada pela implantação e/ou implementação das redes assistenciais locais. Da mesma forma, foi implantado o Programa de Formação de Recursos Humanos Para a Reforma Psiquiátrica, o qual contempla profissionais que trabalham nas redes de atenção à saúde mental e saúde básica, com o mesmo formato para os cursos oferecidos. Estes abordam a questão de álcool e drogas dentro de uma perspectiva ampliada de saúde mental. 
A criação de pólos de capacitação que possam oferecer sistematicamente tais cursos é fundamental, devendo ocorrer pela ação integrada de gestores estaduais e municipais de saúde, bem como de entidades formadoras, aumentando, em nível local, o poder de articulação e mobilização dos diversos programas de saúde, facilitando a participação de demais instituições cuja atividade possua transversalidade com a questão de álcool e drogas.

Ainda no âmbito educacional, deve ser desenvolvido trabalho intersetorial voltado para a revisão e reformulação dos parâmetros curriculares vigentes, garantindo a inclusão consistente de álcool e drogas e DST-AIDS nas grades curriculares escolares. Da mesma forma, devem ser operadas mudanças relativas à formação de profissionais das diversas áreas de saúde, com a inclusão de disciplinas especificamente voltadas para esta área, ou com a remodelação das já existentes, garantindo carga horária teorico-prática suficiente.

A sustentação técnica, política e financeira destas atividades é fundamental e indispensável à sua implantação e/ou implementação.

As ações preventivas devem facilitar a promoção da atenção global aos indivíduos, melhorando o seu acesso a dispositivos de cuidados e à rede de suporte social existente em seu território; devem também facilitar a sua inserção e integração comunitárias, encontrando o seu campo legitimo de atuação na comunidade. Devem, enfim, ajudar a proporcionar ganhos de qualidade de vida para as pessoas, com a facilitação de condições básicas à reconstrução não somente de vivências em que a participação do álcool e das drogas seja nenhuma, mínima ou menos danosa, mas de projetos de vida individualizados que comportem opções mais produtivas e alternativas ao uso de álcool e outras drogas enquanto fonte de prazer, e que detenham uma perspectiva evolutiva real para o futuro destas pessoas.

\subsection{2 - Promoção e Proteção à saúde de consumidores de álcool e outras drogas}

A atenção integral compreende o desenvolvimento contínuo de fatores de proteção, individuais e coletivos na trajetória de vida das pessoas, prevendo a maximização da saúde nos três níveis de atenção.

Em outras palavras, aponta-se a necessidade de potencializar a prevenção institucional, contrária à culpabilização dos sujeitos, oferecendo de fato, subsídios para o enfrentamento da vulnerabilidade das pessoas em geral e especialmente de populações mais vulneráveis, e por conseqüência, com maior probabilidade de exclusão, tais como os usuários de álcool e outras drogas. É necessário se ater a uma posição e a uma visão da saúde que a conceba de forma integral, equânime e justa. Há necessidade, desta forma, de mudança no paradigma de "doentes" para novos cidadãos merecedores de direitos e exercício pleno da cidadania. 
Contudo, ressalta-se que a capacidade de resposta para as ações de prevenção e de promoção à saúde quando analisadas regionalmente, aponta para a necessidade de investimento diferenciado para a promoção desta resposta, tanto pelos níveis governamentais quanto pela sociedade civil.

É necessária a mobilização o debate com a sociedade e o setor legislativo em várias esferas, para a otimização e a construção de arcabouços legais que amparem as ações necessárias.

"Descriminalizar uma conduta longe está de, necessariamente, significar uma ausência de qualquer controle sobre esta conduta. Significa apenas, afastar uma das formas pelas quais se exerce o controle social de condutas sem invadir o âmbito da liberdade individual, mostrando-se igualmente mais racionais, eficazes e menos danosas. Tomemos como exemplo a restrição ao uso de cigarros e outros produtos derivados do tabaco em recintos coletivos, com o que se evitam efeitos eventualmente danosos ou indesejáveis para terceiros, respeitando-se, ao mesmo tempo, a opção individual, com a reserva da área, devidamente isolada e com arejamento conveniente, destinada exclusivamente ao fim de uso daquelas substâncias psicoativas. É nesta mesma linha que podem e devem ser tratados a produção, a distribuição e o consumo de quaisquer outras substâncias psicoativas, abrindo-se maior espaço para o desenvolvimento de políticas que, como a que informa os programas e ações voltados para a redução de danos eventualmente causáveis por um consumo excessivo, descuidado ou descontrolado, daquelas substâncias, verdadeiramente se destinam a preservar e proteger a saúde pública" (Karan, 2003).Também é necessário assegurar a articulação com outros setores bem como a garantia das conquistas já realizadas. Como exemplo, citamos o cumprimento dos parâmetros curriculares que incluem temas de sexualidade e uso de drogas e DST/Aids.

A promoção da saúde, portanto, impõe-se pela complexidade dos problemas que caracterizam a realidade sanitária, em que predominam as doenças crônicas não transmissíveis ao lado de doenças sociais contemporâneas, como a violência e as novas endemias. Configura-se também pela potencialidade de estratégias que superem a cultura da medicalização predominante no imaginário da sociedade.

Desde 1994, o Ministério da Saúde assume a redução de danos como importante estratégia de saúde pública para a prevenção das DST/AIDS e hepatites entre usuários de drogas injetáveis por meio de uma cooperação com o UNDCP - Programa das Nações Unidas para o Controle Internacional de Drogas, constituindo-se o primeiro projeto de redução de danos apoiado por este organismo internacional. Atualmente, o Ministério da Saúde fornece suporte a 160 projetos de redução de danos, oferecendo acesso a 84.000 UDl's, representando uma cobertura de $10 \%$ para esta população específica. Existem no País cerca de 11 leis estaduais e municipais de redução de danos, 02 associações nacionais de redutores de danos e 16 associações estaduais/municipais de redução de danos. 
As ações de redução de danos, mesmo dando prioridade à prevenção e o diagnóstico do HIV por meio de intervenções de troca e distribuição de agulhas e seringas, deram visibilidade aos usuários de drogas injetáveis no SUS, promoveram a organização de profissionais e usuários, trouxeram contribuições significativas para a revisão das leis em vigor e proporcionaram o compartilhamento de saberes técnicos e saberes populares, criando condições para a construção de estratégias que se mostraram eficazes na abordagem dos problemas de saúde dos consumidores de drogas. Hoje se configura, diante do atual cenário a necessidade de sua expansão de forma a contemplar os estilos de vida dos diferentes usuários de álcool e outras drogas, lidando com situações complexas configurando-se num campo de ações transversais e multisetoriais, que misture enfoques e abordagens variadas, ou seja, resgatar sua dimensão de promoção à saúde.

Grandes esforços têm sido feitos para a incorporação das ações de redução de danos no âmbito de outras ações de saúde, tal qual nos Programas de Agentes Comunitários e de Saúde da Família (PACS/PSF), pois tais programas contam com o apoio direto dos municípios que os implementam por meio de recursos próprios, tendo a saúde preventiva como método de ação.

Pode-se medir a efetividade das ações de RD por meio do seu impacto econômico. A prevenção dirigida a UDI por meio de um projeto de redução de danos custa em torno de $U \$ 29,00 / a n o$, ao passo que o tratamento de uma pessoa com AIDS pelo SUS custa em torno de U\$4.000,00/ano

Estudos realizados pelo Ministério da Saúde e a Universidade Federal de Minas Gerais nos anos de 1999 e 2001 demonstram que as ações de redução de danos dirigidas a UDI, promovem a mudança de comportamentos de injeção compartilhada e o uso do preservativo, diminuindo suas vulnerabilidades à infecção ao HIV:

Tabela 1: Resultados de pesquisas realizadas pelo MS e UFMG, em 1999 e 2001:

\begin{tabular}{|l|c|c|}
\hline \multicolumn{1}{|c|}{ Indicadores } & $\mathbf{1 9 9 9}$ & $\mathbf{2 0 0 1}^{2}$ \\
\hline Soroprevalência HIV & $52 \%$ & $36,5 \%$ \\
\hline Soroprevalência HCV & $60 \%$ & $56,4 \%$ \\
\hline Uso do preservativo & & \\
\hline Fez teste anti HIV & $42,1 \%$ & $62,9 \%$ \\
\hline Compartilhamento de agulhas/seringas & $52 \%$ & $66,4 \%$ \\
& & \\
\hline
\end{tabular}

1 - Estudo realizado pela UFMG/MS em 1999, entre 287 UDI, em 05 cidades. 
Outro importante resultado a ser destacado mostra que um UDI vinculado a alguma ação de saúde, no caso um projeto de redução de danos, onde a abordagem prioriza suas necessidades e faz a ligação com o sistema de saúde, tem melhores indicadores comportamentais do que um UDI sem este tipo de relação:

Tabela 2: Principais indicadores comportamentais entre UDI acessados e não acessados por ações de redução de danos

\begin{tabular}{|l|c|c|}
\hline INDICADORES & $\begin{array}{c}\text { UDI Clientes } \\
\mathbf{N}=\mathbf{5 9 9} \\
(\%)\end{array}$ & $\begin{array}{c}\text { UDI Não clientes } \\
\mathbf{N}=\mathbf{2 5 2} \\
(\%)\end{array}$ \\
\hline Soroprevalência positiva para o HIV & 39,3 & 29,9 \\
\hline Seringas e agulhas obtidas no PRD & 86,3 & 26,1 \\
\hline $\begin{array}{l}\text { Compartilhamento de seringas/agulhas nos últimos } \\
\text { meses }\end{array}$ & 40,6 & 50,5 \\
\hline Descarte inadequado no último mês & 75,2 & 100 \\
\hline Tratamento de saúde nos últimos 6 meses & 82,6 & 74,2 \\
\hline Teste HIV na vida & 66,4 & 55,8 \\
\hline Uso do preservativo nos últimos 6 meses & 42,3 & 31,1 \\
\hline
\end{tabular}

Estudo realizado pela UFMG/MS em 2001, entre 869 UDI, em 07 cidades

A estratégia de redução de danos desenvolvida entre UDI mostra-se eficaz e por tanto em condições de ser ampliada junto a usuários de outras drogas, tais como álcool, crack, tabaco, tanto no tocante à disponibilização de insumos para uso seguro, quanto no fortalecimento do protagonismo destes consumidores para a realização de ações entre pares e sua participação na formulação de políticas públicas, estratégias de comunicação e elaboração de materiais educativos.

\subsection{3 - Modelos de Atenção - CAPS e Redes Assistenciais}

A implantação dos serviços de atenção diária, nas diversas modalidades (CAPS I, II, III, infanto-juvenil e álcool/drogas) tem mudado visivelmente o quadro de desassistência que caracterizava a saúde mental pública no Brasil. Ao final de 2002, a rede de atenção em Saúde Mental contava com 382 serviços implantados e em funcionamento, que atendem aproximadamente 120.000 pacientes necessitados de cuidado regular e contínuo. Além destes, 42 CAPSad, modalidade totalmente nova de atenção a uma clientela grave e desassistida, foram implantados de abril a dezembro de 2002, em 14 estados brasileiros. 
A expansão da rede em questão obedece aos desígnios da Reforma Psiquiátrica, sempre buscando viabilizar a substituição do modelo assistencial vigente em saúde mental - ainda predominantemente hospitalocêntrico - por redes de atenção especializadas e compostas por dispositivos extra-hospitalares.

A via de mão dupla da Reforma: declínio dos leitos psiquiátricos e ampliação dos serviços de atenção diária

\begin{tabular}{|l|l|l|l|l|l|l|l|}
\hline Leitos/CAPS & 1996 & 1997 & 1998 & 1999 & 2000 & 2001 & 2002 \\
\hline Leitos HP & 72.514 & 71.041 & 70.323 & 66.393 & 60.868 & 56.258 & 56.258 \\
\hline CAPS & 154 & 176 & 231 & 237 & 253 & 295 & $424^{*}$ \\
\hline
\end{tabular}

Fonte : DATASUS - Área Técnica de Saúde Mental/ASTEC/SAS, 2001

Gestores Municipais e Estaduais de Saúde Mental

* Incluindo os 42 CAPSad implantados em 2002

\section{DISTRIBUIÇÃO DOS 424 CAPS EM FUNCIONAMENTO - BRASIL 2003}

382 CAPS I, II, III ei (em azul, os 42 CAPSad)

0 (1)

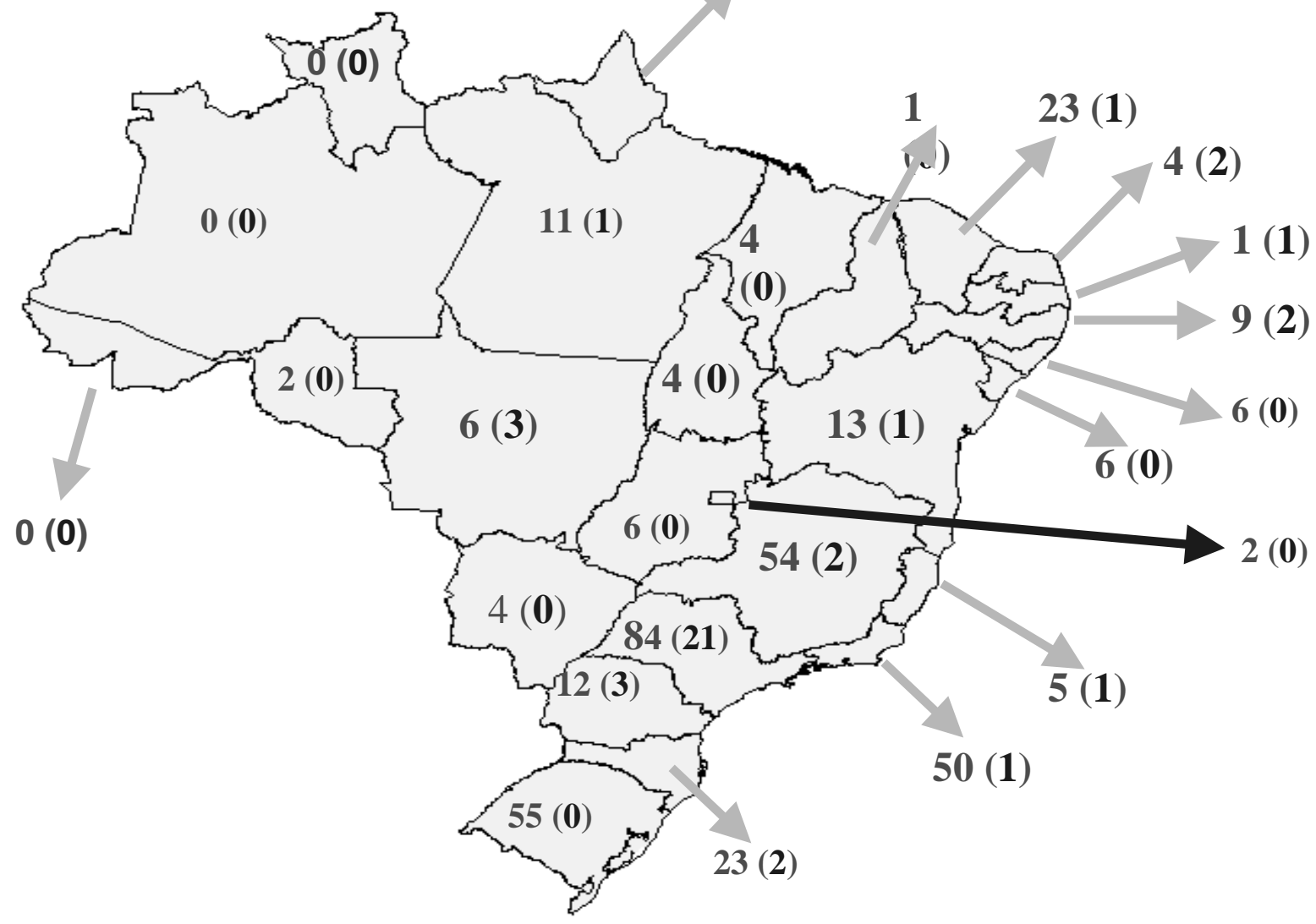


Analisando os dados contidos na Tabela abaixo, verificamos que o maior percentual de gastos é decorrente do uso indevido de álcool (87,9\%); corroborando consenso mundial de que as intervenções voltadas para minimizar os custos do gasto indevido de substâncias psicoativas devem dedicar atenção especial às drogas de uso lícito, especialmente o álcool.

TABELA I - MORBIDADE HOSPITALAR NO SUS - CAP V - TRANSTORNOS MENTAIS DECORRENTES DO USO DE ÁLCOOL E OUTRAS SUBSTÂNCIAS PSICOATIVAS - 1998 A 2001

\begin{tabular}{|c|c|c|c|c|c|c|}
\hline Morbidades - CID-10 & $\mathbf{1 9 8 8}$ & $\mathbf{1 9 9 9}$ & $\mathbf{2 0 0 0}$ & $\mathbf{2 0 0 1}$ & Valor Total & $\begin{array}{c}\text { \% } \\
\text { Gastos }\end{array}$ \\
\hline $\begin{array}{c}\text { Transtornos mentais e } \\
\text { Comportamentais } \\
\text { decorrentes do uso de } \\
\text { álcool }\end{array}$ & 53.731 .366 & 57.152 .025 & 57.489 .540 & 60.145 .523 & 232.518 .454 & $87,9 \%$ \\
\hline $\begin{array}{c}\text { Transtornos mentais e } \\
\text { Comportamentais } \\
\text { decorrentes do uso de } \\
\text { outras substâncias } \\
\text { psicoativas }\end{array}$ & 7.155 .124 & 7.811 .570 & 7.802 .547 & 9.061 .261 & 31.830 .502 & $13,1 \%$ \\
\hline Total gastos anuais & 60.886 .490 & 64.963 .595 & 65.292 .087 & 69.206 .704 & 264.348 .956 & $100 \%$ \\
\hline & & & & & & \\
\hline
\end{tabular}

(Fonte: DATASUS, MS)

A constatação acima se torna mais importante mediante o fato de que poucos consumidores (os mais acometidos, em verdade) recebem atenção do sistema de saúde, e que a atenção hospitalar, em um modelo iatrogênico, ultrapassado e excludente de oferta de cuidados, não contempla as necessidades da maioria dos indivíduos que têm poucos problemas com o álcool, os quais constituem parcela maior da população de consumidores - portanto, com maior probabilidade e risco para desenvolver problemas mais graves, devendo ser alvo de intervenções preventivas, o que não deve ser absolutamente ignorado, dentro de uma perspectiva de saúde pública. Desta forma, prevenção primária e intervenções breves podem ter efeitos benéficos que ultrapassam as suas populações-alvo. A oferta de cuidados extrahospitalares, inseridos na comunidade e complementados por outros programas assistenciais promove condições para a reversão deste panorama.

Analisando a tabela a seguir, podemos observar que tal fato é corroborado pela evolução comparativa entre gastos com as redes hospitalar e substitutiva em Saúde Mental, entre 1997 e 2002. 
TABELA II - EVOLUÇÃO COMPARATIVA ENTRE GASTOS COM REDE HOSPITALAR E REDE SUBSTITUTIVA EM SAÚDE MENTAL - 1997 / 2002 - BRASIL

\begin{tabular}{|c|c|c|c|c|c|c|}
\hline $\begin{array}{c}\text { Totais de } \\
\text { gastos (em } \\
\text { R\$) }\end{array}$ & 1997 & 1998 & 1999 & 2000 & 2001 & 2002 \\
\hline $\begin{array}{c}\text { Total } \\
\text { Hospitalar }\end{array}$ & 379.667 .296 & 422.058 .386 & 461.906 .622 & 463.324 .089 & 479.360 .210 & 466.000 .000 \\
\hline $\begin{array}{c}\text { Total } \\
\text { substitutivo }\end{array}$ & 27.945 .351 & 37.169 .456 & 47.443 .107 & 87.089 .369 & 99.880 .438 & 119.000 .000 \\
\hline $\begin{array}{c}\text { TOTAL } \\
\text { GERAL }\end{array}$ & 407.612 .647 & 459.227 .842 & 509.349 .729 & 550.413 .458 & 579.240 .648 & 585.000 .000 \\
\hline $\begin{array}{c}\text { \% gastos } \\
\text { hospitalares / } \\
\text { substitutivos }\end{array}$ & 93,14 & 91,91 & 90,69 & 84,18 & 82,76 & 79,69 \\
\hline
\end{tabular}

(Fonte: Área Técnica de Saúde Mental / DATASUS)

A expansão da rede especializada de cuidados em saúde mental / álcool e drogas segue alguns critérios objetivos:

1. população do município ou micro-região a ser atendida;

2. ausência de recursos assistenciais, configurando baixo acesso ao atendimento;

3. maior risco/vulnerabilidade, em função de indicadores epidemiológicos e sociais;

4. existência de hospital psiquiátrico, e conseqüente programa de desinstitucionalização, com residências terapêuticas e outros dispositivos para a reintegração social de pacientes de longa permanência hospitalar.

Somente no ano de 2002, o SUS gastou $\mathrm{R} \$ 74.447 .824,64$ com 96.295 internações psiquiátricas hospitalares relativas a transtornos decorrentes do uso abusivo / dependência de álcool e outras drogas (DATASUS, 2002). Estes dados são subestimados, devido a limitações relacionadas à notificação dos agravos não previstos pelo sistema (ex.: distúrbios gastrintestinais, endocardites, overdoses e outros), também de custo bastante elevado.

\begin{tabular}{|c|c|c|}
\hline ANO & N o Internações Psiquiátricas & Valor Gasto \\
\hline 1998 & 101.794 & $60.886 .490,12$ \\
\hline 1999 & 99.542 & $64.963 .594,86$ \\
\hline 2000 & 97.958 & $65.292 .087,38$ \\
\hline 2001 & 98.652 & $69.206 .783,79$ \\
\hline 2002 & 96.295 & $74.447 .824,64$ \\
\hline
\end{tabular}

(DATASUS, 2002) 
A estimativa máxima de pacientes em atendimento regular na rede de 42 CAPSad: é de 95.760 (Portaria SAS 189 de 20 de março de 2002), a um custo anual aproximado de $R \$ 13.443 .277,68$ para um número máximo de 942.480 atendimentos possíveis às mesmas 42 unidades CAPSad já implantadas. Ou seja, em uma comparação sumaria com o custo decorrente das internações referentes a 2002, os CAPSad possibilitam dez vezes mais atendimentos, a um custo cinco vezes menor, e com maior qualidade de atenção..

O estabelecimento de uma forma estratégica de financiar os serviços é crucial para sua expansão, consolidação e fortalecimento. Estamos tratando de tecnologia nova de atenção, em uma área de problemas que, em geral, não suscita aos gestores e à própria população uma angústia pela ampliação da cobertura, de modo proporcional à gravidade do quadro epidemiológico. De fato, os problemas mentais - embora apareçam no imaginário social e sanitário como sempre graves, dramáticos e visíveis - são em sua maioria silenciosos, mortificantes e invisíveis aos olhos. O dispositivo do CAPS, fazendo um uso deliberado e eficaz dos conceitos de território e rede, realiza uma procura ativa e sistemática das necessidades a serem atendidas, representando uma eficiente ação de prevenção secundária dos transtornos mentais severos e persistentes.

Um CAPSad tem como objetivo oferecer atendimento à população, respeitando uma área de abrangência definida, oferecendo atividades terapêuticas e preventivas à comunidade, buscando:

1. Prestar atendimento diário aos usuários dos serviços, dentro da lógica de redução de danos;

2. Gerenciar os casos, oferecendo cuidados personalizados;

3. Oferecer atendimento ns modalidades intensiva, semi-intensiva e não-intensiva, garantindo que os usuários de álcool e outras drogas recebam atenção e acolhimento;

4. Oferecer condições para o repouso e desintoxicação ambulatorial de usuários que necessitem de tais cuidados;

5. Oferecer cuidados aos familiares dos usuários dos serviços;

6. Promover, mediante diversas ações (que envolvam trabalho, cultura, lazer, esclarecimento e educação da população), a reinserção social dos usuários, utilizando para tanto recursos intersetoriais, ou seja, de setores como educação, esporte, cultura e lazer, montando estratégias conjuntas para o enfrentamento dos problemas;

7. Trabalhar, junto a usuários e familiares, os fatores de proteção para o uso e dependência de substâncias psicoativas, buscando ao mesmo tempo minimizar a influência dos fatores de risco para tal consumo;

8. Trabalhar a diminuição do estigma e preconceito relativos ao uso de substâncias psicoativas, mediante atividades de cunho preventivo / educativo.

A lógica da redução de danos contempla um conjunto de medidas de saúde que buscam minimizar as conseqüências do uso e dependência de substâncias psicoativas, bem como diminuir o risco de infecção por hepatites e HIV. O uso destas medidas permite que sejam elaborados projetos terapêuticos mais 
flexíveis e de menor exigência, conseqüentemente adequados às necessidades de cada usuário dos serviços.

Os CAPSad também podem ter a responsabilidade de organizar a rede local de serviços de atenção a usuários de álcool e drogas de seu território de atuação, a saber:

1. Quando são a porta de entrada da rede de atenção a usuários de álcool e drogas, em sua área de atuação;

2. Quando o gestor local indica a unidade para coordenar as atividades de supervisão de serviços de atenção a usuários de drogas;

3. Devem ainda supervisionar e capacitar as equipes de atenção básica, serviços e programas de saúde mental, no âmbito de seu território;

4. Devem também manter listagem atualizada dos pacientes que, em sua região de abrangência, utilizem medicamentos para a saúde mental.

Para definir as suas estratégias de atuação, um CAPSad deve considerar obrigatoriamente que a atenção psicossocial a pacientes que apresentam uso abusivo/dependência de álcool e outras drogas deve ocorrer em ambiente comunitário, de forma integrada à cultura local, e articulada com o restante das redes de cuidados em álcool e drogas e saúde mental; o mesmo deve ocorrer em relação a iniciativas relativas à rede de suporte social. Desta forma, poderá organizar em seu território de atuação os serviços e iniciativas que possam atender às múltiplas necessidades dos usuários de serviços, com ênfase na reabilitação e reinserção social dos mesmos.

A vulnerabilidade para o uso indevido de álcool e drogas é maior em indivíduos que estão insatisfeitos com a sua qualidade de vida, possuem saúde deficiente, não detêm informações minimamente adequadas sobre a questão de álcool e drogas, possuem fácil acesso às substâncias e integração comunitária deficiente. Também vale a pena ressaltar que, se existem fatores de risco - características ou atributos de um indivíduo, grupo ou ambiente de convívio social, que contribuem para aumentar a ocorrência do uso indevido de álcool e drogas - também existem fatores específicos de proteção para este mesmo uso. Fatores de risco e de proteção podem ser identificados em todos os domínios da vida: nos próprios indivíduos, em suas famílias, em seus pares, em suas escolas e nas comunidades, e em qualquer outro nível de convivência sócio-ambiental; estando interligados de forma consistente.

Desta forma, se as manifestações do uso indevido de álcool e drogas encontram seu lugar na comunidade, é neste ambiente que terão lugar as práticas terapêuticas, preventivas e educativas de maior impacto sobre os chamados fatores de risco para este uso indevido.

Os CAPSad devem oferecer atendimento diário, sendo capazes de oferecer atendimento nas modalidades intensiva, semi-intensiva e não-intensiva, permitindo o planejamento terapêutico dentro de uma perspectiva individualizada de evolução contínua. Possibilita ainda intervenções precoces, limitando o estigma associado ao tratamento. Assim, a rede proposta se baseia nestes serviços comunitários, apoiados por leitos psiquiátricos em hospital geral e outras práticas de atenção comunitária (ex.: 
internação domiciliar, discussão comunitária de serviços), de acordo com as necessidades da população-alvo dos trabalhos.

Os CAPSad atuam de forma articulada a outros dispositivos assistenciais em saúde mental (ambulatórios, leitos em hospital-geral, hospitais-dia) e da rede básica de saúde (unidades básicas de saúde, etc), bem como ao Programa de Saúde da Família e ao Programa de Agentes Comunitários de Saúde; também se articulam em torno dos dispositivos de suporte social já existentes nas comunidades, configurando redes flexíveis de cuidados, que possam responder por um determinado território populacional, e que se remodelem de forma dinâmica, mediante a necessidade de inclusão/exclusão de novos serviços e formas de cuidado, de forma pareada pela demanda assistencial.

Os CAPSad oferecem atenção ambulatorial diária aos dependentes químicos, desenvolvendo uma gama de atividades que vão desde o atendimento individual (medicamentoso, psicoterápico, de orientação, entre outros), até atendimentos em grupo ou oficinas terapêuticas e visitas domiciliares.

Também devem oferecer condições para o repouso dos usuários de serviços, bem como para a desintoxicação ambulatorial de pacientes que necessitem deste tipo de cuidados, e que não demandem por atenção clínica hospitalar.

Em todo o mundo, a abordagem terapêutica dentro de uma lógica de redução de danos tem apresentado resultados positivos, e vem assumindo importância considerável no tratamento de usuários de drogas. Desta forma, os CAPSad devem se utilizar dos recursos terapêuticos disponíveis para promover, o mais amplamente possível, a reabilitação psicossocial e a reinserção social de seus usuários.

A prevenção voltada para o uso abusivo e/ou dependência de álcool e outras drogas pode ser definida como um processo de planejamento, implantação e implementação de múltiplas estratégias voltadas para a diminuição da vulnerabilidade/redução dos fatores de risco específicos, e fortalecimento dos fatores de proteção. Implica necessariamente em inserção comunitária das práticas propostas, com a colaboração de todos os segmentos sociais disponíveis.

A lógica que sustenta tal planejamento deve ser a da redução de danos, em uma ampla perspectiva de práticas voltadas para minimizar as conseqüências globais de uso de álcool e drogas. O planejamento de programas assistenciais de menor exigência contempla uma parcela maior da população, dentro de uma perspectiva de saúde pública, o que encontra o devido respaldo em propostas mais flexíveis, que não tenham a abstinência total como a única meta viável e possível aos usuários dos serviços CAPSad, e outros não-especializados.

Por sua característica de serviço aberto e comunitário, o CAPSad pode oferecer programas terapêuticos de menor nível de exigência, portanto disponíveis a mais pessoas da comunidade. As modalidades de cuidados para álcool e drogas nas unidades CAPSad devem obedecer a uma lógica de redução de danos, seja esta relativa a práticas voltadas para DST/HIV/AIDS, seja em relação ao próprio uso 
indevido de álcool e drogas (ex.: intervenções breves para adolescentes que fazem uso de álcool em um padrão abusivo).

Devemos ressaltar o enorme potencial benéfico desta lógica, em termos de saúde pública; ao considerarmos somente o fato de que a faixa etária mais acometida pelo HIV gravita em torno de 25-35 anos de idade, e considerando também que o vírus pode permanecer de forma silenciosa no organismo por até 10 anos, vemos aqui uma irrefutável justificativa para a ampla utilização de práticas preventivas e os CAPS contemplam a atuação comunitária, nos planos preventivo terapêutico/educativo.

Conforme mencionado anteriormente, o planejamento de ações voltadas para minimizar os efeitos adversos do uso de álcool e drogas deve identificar fatores de risco e proteção; desta forma, deve contemplar práticas que favoreçam a minimização dos fatores de risco para o consumo destas substâncias, de forma paralela ao reforço de fatores de proteção.

\subsubsection{Controle de Entorpecentes e Substâncias que Produzem Dependência Física ou Psíquica, e de Precursores - Padronização de Serviços de Atenção à Dependência Química}

Os distúrbios e as seqüelas ocasionadas pelo abuso de álcool e pelo uso de outras drogas têm se destacado como importante problema de saúde pública no Brasil e no Mundo.

As questões relacionadas às drogas, pela sua complexidade, reclamam ações coordenadas em vários campos, exigindo a atuação conjunta das políticas governamentais de saúde, justiça, educação, direitos humanos, trabalho, comunicação e cidadania nesta área.

No campo da saúde pública, além das atividades de prevenção e de assistência às pessoas com problemas decorrentes do uso ou abuso de substâncias entorpecentes e psicotrópicos, se faz necessário o controle das drogas lícitas utilizadas em medicina, compreendendo a sua fabricação, distribuição, prescrição e venda, bem como o estabelecimento de padrões para o funcionamento de serviços voltados à prevenção e recuperação.

As ações de controle e fiscalização do uso lícito de substâncias e medicamentos sujeitos a controle especial no Brasil, incluídos os entorpecentes e psicotrópicos, são executadas pelo Ministério da Saúde sob o amparo no art. 6으 da Lei no 6368/76 que reza:

Art. 6으 - Compete privativamente ao Ministério da Saúde, através de seus órgãos especializados, baixar instruções de caráter geral ou especial sobre proibição, limitação, fiscalização e controle da produção, do comércio e do uso de substâncias entorpecentes ou que determinem dependência física ou psíquica e de especialidades farmacêuticas que as contenham. 
Esta competência, por força da Lei ํo 9782/99, cabe à Agência Nacional de Vigilância Sanitária ANVISA, órgão federal de regulação no SUS, instituído para ser conseqüente com a missão do poder público a ele atribuído, - "de proteger e promover a saúde do conjunto da população brasileira, garantindo a segurança sanitária de produtos e de serviços”, conforme está explicitado na Lei 8080/90.

Em 2002 a Lei № 10.409 amplia a atribuição do Ministério da Saúde para controle dos precursores, ficando a ANVISA com a responsabilidade institucional do controle da grande maioria dos precursores definidos na Convenção das Nações Unidas Contra o Tráfico de Entorpecentes e Psicotrópicos, de acordo com a Portaria SVS/MS no 344/98 (lista D1).

De outro lado, o vazio de possibilidades para a reabilitação das pessoas com dependência ao álcool ou a outras drogas possibilitou a instalação no Brasil de serviços autodenominados de "Comunidades Terapêuticas". Estes serviços multiplicaram-se sem qualquer regulamentação, evidenciando-se um funcionamento precário para muitos deles, tendo sido determinado pelo Conselho Nacional Antidrogas CONAD o estabelecimento de um padrão básico para funcionamento dos mesmos, assegurando direitos e um mínimo de qualidade aos usuários.

Desta forma, a ANVISA, por meio da Resolução da Diretoria Colegiada de № 101/2001, publicada em 31 de maio de 2001, estabeleceu o Regulamento Técnico para o Funcionamento de Serviços de Atenção a Pessoas com Problemas Decorrentes do Uso ou Abuso de Substâncias Psicoativas, Segundo Modelo Psicossocial, também denominados de "Comunidades Terapêuticas". A construção desta proposta de regulamento foi elaborada por Grupo de Trabalho coordenado pela ANVISA, integrado por representantes da Coordenação de DST/AIDS e da Assessoria de Saúde Mental da Secretaria de Assistência à Saúde do Ministério da Saúde (MS, 1999), com contribuições de órgãos e entidades envolvidas na assistência às pessoas com problemas de dependência química.

Com estas atribuições a ANVISA inclui-se entre os atores que abraçam o desafio do enfrentamento das questões referentes a álcool e drogas, um dos grandes desafios da sociedade contemporânea com seus determinantes psíquicos, sociais e econômicos. 


\section{BIBLIOGRAFIA}

Benevides de Barros, $R$ \& Passos, E Clinica e biopolítica na experiência do contemporâneo. Psicologia Clínica. Rio de Janeiro. PUC/RJ. CTCH, Departamento de Psicologia, v.13, no. 1, 2001, p:91.

Brasil. Ministério da Saúde. Política Nacional de Redução da Morbimortalidade por Acidentes e Violências - Brasília, 2001.

Brasil, Ministério da Saúde, Secretaria Executiva. Legislação em Saúde Mental 1990-2002. 3ª Edição. Brasília, Ministério da Saúde, 2002

Brasil, Ministério da Saúde. Sistema Único de Saúde. Conselho Nacional de Saúde. Comissão Organizadora da III CNSM. Relatório Final da III Conferência Nacional de Saúde Mental. Brasília, 11 a 15 de dezembro de 2001. Conselho Nacional de Saúde / MS, 2002

Brasil, Ministério da Saúde. Relatório do seminário sobre o atendimento aos usuários de álcool e outras drogas na rede do SUS. Caderno de Textos de Apoio da III Conferência Nacional de Saúde Mental. MS, Brasília, 2001

Brasil, Ministério da Saúde, Coordenação da Área Técnica de Saúde Mental. Proposta de Normalização dos Serviços de Atenção a Transtornos por Uso e Abuso de Substâncias Psicoativas. Brasília, 1999

Brasil, Ministério da Saúde, Ministério da Justiça. Reforma Psiquiátrica e Manicômios Judiciários; Relatório Final do Seminário Nacional para a reorientação dos Hospitais de Custodia e Tratamento Psiquiátrico. Brasília, Ministério da Saúde, 2002.

Brasil. Universidade Federal da Bahia. Instituto de Saúde Coletiva. Prefeitura Municipal de Salvador. Plano Intersetorial e Modular de Ação para a Promoção da Paz e da Qualidade de Vida na Cidade de Salvador. 2000.

Câmara dos Deputados. Seminário Direito à Saúde Mental: Regulamentação e Aplicação da Lei 10.216. Brasília, Câmara dos Deputados, 2002

CARLINI, EA; GLADURÓZ, JC; NOTO, AR, NAPPO, AS. I Levantamento domiciliar sobre o uso de drogas psicotrópicas no Brasil. São Paulo: CEBRID, Centro Brasileiro de Informações sobre as Drogas Psicotrópicas. UNIFESP, 325-328, 2002.

Crisp, A H., Gelder, M.G. Stigmatization of people with mental ilnesses. The British Journal of Psychiatry, (2000) 177: 4-7

Delgado, P.G. O SUS e a Lei 10.216: Reforma Psiquiátrica e Inclusão Social. Em "Saúde Mental e Qualidade de Vida". Loyola, C. e Macedo, P. Organizadores. Edições CUCA / UPUB, Rio de Janeiro, 2002

Edwards, G. Marshall, EJ. Cook, C.C.H. The treatment of Drinking problems: a guide to helping professions, third edition. Cambridge University Press, Cambridge, 1997

Galduróz, J.C.; Noto, A. R.; Carlini, E. A.. IV Levantamento sobre o uso de drogas entre estudantes de 1ำ e $2^{\circ}$ graus em 10 capitais brasileiras - 1997. Centro Brasileiro de Informações sobre Drogas Psicotrópicas - CEBRID, Escola Paulista de Medicina, 1997

Greve JMD, Leyton V. Alterações Clínicas por ingestão de cerveja X alcoolemia direta. Simpósio Álcool e suas repercussões sociais, 1999. 
Greve JMD e Cols. Álcool em vítimas de causas externas atendidas no Pronto Socorro Central do Hospital das Clínicas da Faculdade de Medicina da Universidade de São Paulo, 1999.

IPEA/MS e Cols. Impactos sociais e econômicos dos acidentes de transito nas aglomerações urbanas., em desenvolvimento.

Karan, M. L. Drogas, proibições e danos - no prelo. 2003.

Marlatt, G. Alan. Redução de danos: estratégias práticas para lidar com comportamentos de alto risco. Porto Alegre, Artes Medicas Sul, 1999

Murray, C.J.L. Lopez, AD. The global burden of disease: a comprehensive assessment of mortality and disability, form diseases, injuries and risk factors in 1990 and projected to 2020. Cambridge, Massachusetts Harvard School of Public Health to World Health Organization and World Bank. Global Burden of Disease and Injury Series, Vol I, 1996

Nery, AF e Cols. Impacto do uso de Álcool e outras Drogas em Vítimas de Acidentes de Trânsito. ABDETRAN, Brasília, 1997.

NIDA. Infofacts: Costs to Society. The National Institute on Drug Abuse. National Institute of Health, The US. Department of Health and Human Services. USA, 2002

NIDA. Principles of Drug Addiction Treatment: a Research-Based Guide. Bethesda, Maryland, The National Institute on Drug Abuse. National Institute of Health, The US. Department of Health and Human Services. USA, 2001

Noto, A R.. O uso de drogas entre crianças e adolescentes em situação de rua de seis capitais brasileiras no ano de 1997. Tese de Doutorado. UNIFESP/EPM, São Paulo, 1998

Organização Mundial da Saúde. Classificação Internacional de Transtornos Mentais e de Comportamento da CID-10. Ed. Artes Médicas, Porto Alegre, 1996

Organização Mundial da Saúde. Relatório sobre a Saúde no Mundo 2001 - Saúde Mental: Nova Concepção, Nova Esperança. OMS, Genebra, 2001

PAIM, J.S. 1980. "As ambigüidades da noção de necessidade em saúde" in Planejamento. Salvador. 8 (1/2), pp. 39-46.

VAISSMAN, M. Alcoolismo como problema de saúde no trabalho. Avaliação de um programa de tratamento para funcionários de uma universidade. Tese de doutorado. Rio de Janeiro, UFRJ/IPUB/PROPPSAM, 1998. 


\title{
6. ENDERECOS PARA CONTATOS E INFORMAÇÕES
}

\subsection{Ministeriais}

\section{MINISTÉRIO DA SAÚDE}

www.saúde.gov.br

Informações gerais sobre o SUS, programas de saúde e links importantes.

\section{DISQUE SAÚDE}

\section{MINISTÉRIO DA SAÚDE}

0800-61-

Serviço telefônico gratuito para esclarecimentos à população em geral.

\section{COORDENAÇÃO NACIONAL DE DST E AIDS}

\section{MINISTÉRIO DA SAÚDE}

www.aids.gov.br

Informações gerais sobre as doenças sexualmente transmissíveis, locais para a realização do teste antihiv, publicações e materiais educativos e instrucionais.

\section{ÁREA TÉCNICA DE SAÚDE MENTAL}

Departamento de Ações Programáticas Estratégicas (DAPE)

Secretaria de Atenção à Saúde (SAS)

Fone: 061-315-3315 Fax 061-315-3403

saudemental@saude.gov.br

\subsection{Coordenações Estaduais de Saúde Mental}

\section{ACRE}

Coordenação da área Técnica de Saúde Mental/

Coord. de Saúde Comunitária-DABS/SESACRE

Rua Antônio da Rocha Viana, 1296

Fone(68)2232396/Fax(68)2234688/2232396

RIO BRANCO - AC - CEP 69914-610

\author{
AMAZONAS \\ Programa de Saúde Mental/Gerência de Políticas de Saúde \\ AV.André Araújo,701-Aleixo \\ Fone: (92) 6634826/6637313 \\ MANAUS - AM - CEP 69060-001

\section{Amapá} \\ Secretaria de Saúde do Amapá \\ Coordenação de Saúde Mental \\ Av. FAB, 69 - Centro - Macapá - AP CEP 68900-000 \\ Fone(96)2126136/fax(96)2126102

\section{PARÁ} \\ Secretaria de Saúde do Pará \\ Diretoria Operacional/DASE/Divisão de Saúde Mental \\ Rua:Presidente Pernambuco,894 - Bairro Batista Campos \\ BELÉM - PA CEP: $66015-200$ \\ Fone/FAX: (91) 241-9355/2239438 - Geral:(91)2244011
}




\section{RONDÔNIA}

SECRETARIA DE SAÚDE DE RONDÔNIA/SESAU/RO

COORDENAÇÃo Estadual de SAÚde MENTAL/GASS

End.Prof:Rua Padre Ângelo Serri, $s / n^{\circ}$ Esplanada das Secretarias Bairro Pedrinhas

PORTO VELHO - RO - CEP 78903-430

Fone: (69) 229-2922/216 5260

Fax: (69)229-3922 / 2915/2165260

\section{RORAIMA}

Secretaria de Saúde de Roraima

Coordenação de Saúde Mental

Rua brigadeiro Eduardo Gomes s/n Campo de Paricarama

BOA VISTA - RR - CEP 69301-000

Fone: (95) 625-3342/3030

\section{TOCANTINS}

Secretaria de Saúde de Tocantins

Coordenação de Saúde Mental

SESAU-Esplanada das Secretarias S/N - AANO S/N

PALMAS - TO - CEP 77085-040

Fone: (63) 218-1787/1716

Fax: (63) 218-1796

ALAGOAS

Coordenação Estadual de Saúde - CESM

Av.da Paz, 1068 - Jaraguá

Fone:cel.(82)9974 2497 - Fone/Fax:(82) 3151682

MACÉIO - ALAGOAS - CEP 57050-000

\section{BAHIA}

Secretaria Estadual de Saúde da Bahia

Programa Estadual de Saúde Mental

Av.Anita Garibaldi,1133 sl.109/110 - Ondina

SALVADOR - BA - CEP 40210-070

Fone: (71) 3704381 - Fax: (71) 3708399 / 3711651

\section{CEARÁ}

Secretaria de Saúde do Estado do Ceará CEADI - Célula de Atenção ao Adulto e Idoso

Av.Santos Dumont,1740 sls. 202/204 - Aldeota

FORTALEZA - CE - CEP 60150-160

Fone: (85) 488-9931/Fax: (85) 488-5888

\section{MARANHÃO}

Gerência de Estado de Qualidade de Vida

Gerência Adjunta de Saúde/Coordenacao de Saúde Mental

Av. Prof. Carlos Cunha, S/N - Jaracati

SÃO LUIS - MA - CEP 65000-000

Fone: (98) 246-5132 


\section{PARAíba}

Secretaria Estadual de Saúde da Paraíba Núcleo de Saúde Mental

Rua Dr.Pedro II, 1826- Torre

JOÃO PESSOA - PB

CEP 58040-903 Fone: (83) 241-1718 R:7025/2187325/2449695

\section{PERNAMBUCO}

Secretaria Estadual de Saúde de Pernambuco Coordenação de Saúde Mental

Praça Oswaldo Cruz, s/n - Bairro Boa Vista

RECIFE - PE - CEP 50050-210

Fone/Fax: 34126182/6342/3423 5696

\section{Piauí}

Secretaria Estadual de Saúde do Piauí Departamento de Ações Especiais de Saúde - DAES Avenida Pedro Freitas, $s / n^{\circ}$ Bloco A Centro Adm. Resid.:Alberone Lemos, 726,Acarapé Cep:64003-780

TERESINA - PI - CEP 64018-200

Fone: (86) 222-78 61/221-6759 - Fax: (86) 222- 7861

\section{RIO GRANDE DO NORTE}

Secretaria Estadual de Saúde do Rio Grande do Norte Coordenação de Saúde Mental

Av. Junqueira Aires, 488 - Cidade Alta

NATAL - RN - CEP $59025-280$

Fone: (84) 232-2571 - Fax: (84) 232-2577/232-2590

\section{SERGIPE}

Secretaria Estadual da Saúde de Sergipe

Coordenação de Saúde Mental Rua Mato Grosso , 880

ARACAJU - SE - CEP 49010-520

Fone: (79) 211-9565 R: 257/Fax:ramal 255

Fax: (79) 224-2073(dimapa)/ 4111754

\section{Paraná}

Secretaria de Estado da Saúde Coordenação de Saúde Mental Rua Piriqui, 170 - Rebouças

CURITIBA - PR - CEP 80230-140

Fone: (41) 3304549/4526(SESA)/263 1053 - Fax: (41) 3304407

\section{RIO GRANDE DO SUL}

Secretaria Estadual de Saúde Coordenação de Atenção Integral à Saúde Mental 
Av. Borges de Medeiros, 1501 - 5 andar - Sala 8

PORTO ALEGRE - RS - CEP 91119-900

Fone: (51) 32885909/ 32885908/ Fax: (51)3225-7688

\title{
SANTA CATARINA
}

Secretaria Estadual de Saúde

Coordenação de Saúde Mental

IPQ - Rua EngilbertoKoerish,s/n -Santana - São José

FLORIANÓPOLIS - SC

Fone: (48) 2780101 Ramal110- (48) 278 0128/ 99582063

\section{ESPÍRITO SANTO}

Secretaria Estadual de Saúde

Superintendência de Planejamento Epidemiologia e Informações/Vigilância Epidemiológica Saúde Mental - SPEI

Avenida Marechal Mascarenhas de Moraes (Beira Mar),2025-Bento Ferreira

VITÓRIA - ES - CEP 29021-120

Fone: (27) 3137-2365/3137 2354 - Fax: (27) 3137-2480/31372311

\author{
MINAS GERAIS \\ Secretaria Estadual de Saúde \\ Superintendência Operacional de Saúde \\ Coordenação de Saúde Mental \\ Avenida Afonso Pena 2300 - 9aadar - Sala 905-Funcionários \\ BELO HORIZONTE - MG - CEP 30130-007 \\ Fone: (31) 3261 4986/9903 4223/3261 5571 - Fax: (31) 32616103
}

\section{RIO DE JANEIRO}

Secretaria de Estado de Saúde

Assessoria de Saúde Mental

Rua México, $128-4^{\circ}$ andar

RIO DE JANEIRO - RJ - CEP 20.031-142

Fone(21) 96043695/ (21) 22448174

Fone/Fax:(21)22407471

\section{SÃO PAULO}

Secretaria Estadual de Saúde de São Paulo

Coordenação de Saúde Mental

Rua dos Franceses, 498 ap.81-BI.F

SÃO PAULO - SP - CEP 01329-010

Fone: (11) 287 4140/ (71) 3352548 / Fax: (11) 3061-3914/3066 8731

\section{DISTRITO FEDERAL}

Coordenação de Saúde Mental

Secretaria Estadual de Saúde

SHS Quadra 301 - Ed. Pioneiras Sociais - 8andar

Fone (061) 325-4873/4856 


\section{GOIÁs}

Secretaria Estadual de Goiás

Departamento de Promoção à Saúde

Av. Anhanguera 5195 - Setor. Coimbra

GOIÂNIA - GO - CEP 74043-011

Fone: (62) 233-3601/291-5022 R.207/Cel.:96212339(Mabel)/ 2826869 (res)

Fax: (62) 233-3601

e-mail:sabsgo@fns.rigi.br; mabelcala@yahoo.com.br

MATO GROSSO DO SUL

Coordenação de Promoção da Saúde

Núcleo de Saúde Mental - Parque dos Poderes

CAMPO GRANDE - MS - CEP 79031-902

Fone: (67) 326-8955/326-4713/Fax: (67) 326-8955

\section{MATO GROSSO}

Secretaria Estadual de Saúde

Área Técnica de Saúde Mental

Centro Político-Administrativo- CPA - Bloco 5

CUIABÁ - MT - CEP 78050-970

Fone: (65) 613 5338/5339/5340

\subsection{CAPSad Implantados e Cadastrados no Ministério da Saúde}

\section{Amapá}

Centro Amapaense de Prevenção e Tratamento ao Abuso de Substâncias Psicoativas - CAPTA

Rua Aurino Borges de Oliveira, 103 - São Lázaro - Macapá, AP

Fone: 96 - 212.1148 / fax 2121123

Resp.: Márcia Gomes Godinho Valentim

Bahia

$\underline{\text { Centro de Estudos de Álcool e Drogas - CAPSad }}$

Praça João Gonçalves, S/N - Centro - Vitória da Conquista, BA - CEP.: 45000-000

Fone: 77 - 424.8545 / 424.8943 - Resp.:Claudinésia Rocha de Oliveira - www.pmvc.com.br

Ceará

\section{CAPSad II de Sobral}

Rua Cel. Mont'Alberne, 769 - Sobral, CE CEP 62011210

Dr. Helian Nunes de Oliveira - 088-6112002 / Fax 6147015 - helian@sobral.org 


\section{Espírito Santo}

Centro de Prevenção e Tratamento de Toxicômanos

Rua Álvaro Sarlo, Ilha de Santa Maria - Vitória, ES

CEP.: 29040-400 - Fone. 27- 31325104 / 2351871

Dir.: Inez Maria Antunes Paz Torres

\section{Mato Grosso}

Centro de Atenção Psicossocial ao Dependente Químico - CIAPS

Rua Itaparica, S/N - Cuiabá, MT - CEP.: 78070-970

Fone: 65 - 661.3588 / 613.5339 - Resp.: Marisa Helena Alves Batista

Centro de Atenção Psicossocial - CAPSad

Quadra 04 - Loteamento São Sebastião II - São Sebastião II - Barra do Garças, MT - CEP.: 78600-000

Fone: (066) 4022042 - Resp.: Eduardo dos Santos Vieira / (066) 99882526 - 4051054

Centro de Atenção Psicossocial para Usuários Dependentes de Álcool e Drogas - CAPSad

Av. Tiradentes, 2507 - Centro - Rondonópolis, MT

CEP 78700-000 - Fone: (0xx66) 4236400

Coord.: Dra. Deyse Pimentel Lopes / (0xx66) 4213138/99543198

\section{Minas Gerais}

Centro de Atenção Psicossocial ao Dependente Químico - CAPSad

Rua Vigário Silva, 561 - Centro - Uberaba, MG

Fone: 343322.3007 / 3312.7912 - Coord.: Odila Maria Fernandes Braga

CAPSad II - Centro Mineiro de Toxicomania

Alameda Ezequiel Dias, 365 - Santa Efigênia - Belo Horizonte, MG

Dir.: José Sebastião Menezes Fernandes

Pará

Centro de Atenção Psicossocial para Usuários Dependentes de Álcool e Drogas - CAPSad

Rua Senador Manoel Barata, 869 - Belém, PA - (091) 2416710 / fax 2414106

Coord.: Rodolfo Valentim do Nascimento - deas@sesma.belem.pa.gov.br

\section{Paraíba}

\section{CAPS Jovem Cidadão}

Rua Leonardo Arcoverde, 250 - Jaguaribe - João Pessoa, PB Fone: 83218.7379 / 218.5902

\section{Paraná}

CAPSad de Maringá

Rua das Camélias, nº 32 - Maringá, PR

Fone: 42 - 218.3172 
Rua. Cel. Hoche Pedro Pires, 475 - Vila Isabel - Curitiba - PR - CEP.: 80240-510

Coord.: Simone Marie Perotta - (041) 2435859 - centrovida@hotmail.com

Núcleo de Atenção Psicossocial do Hospital Pinel Ltda. Rua Irmã Flávia Borlet, 217 - Vila Hauer - Curitiba, PR - CEP.: 81630-170

Fone: (041) 2785374 - Resp.: Dr. Helio Rotemberg

\section{Pernambuco}

Centro Eulâmpio Cordeiro de Recuperação Humana

Rua Rondônia, nำ100 - Bairro Cordeiro - Recife, PE - Fone:81 3228.3200

CPTRA - Centro de Prevenção, Tratamento e Reabilitação do Alcoolismo

Av. Cons. Rosa e Silva, 2130 - Tamarineira - Recife, PE

Rio de Janeiro

\section{Centro de Atenção Psicossocial Dr. Ari Viana}

Rua Viveiros de Vasconcelos, № 359 - Campos dos Goytacazes, RJ

Coord.: Glória Lúcia Bruno Bárbara - (0xx22) 27225096

Rio Grande do Norte

\section{CAPS Leste AD}

Rua Prof. Manoel Dantas, nº 424 - Petrópolis - Natal, RN - Fone: 84 - 322.8565

CAPS Norte AD

Av. Paulistana, 2109 - Natal, RN - Fone.: 84-2328565

\section{Santa Catarina}

\section{Centro de Atenção Psicossocial II ad}

Rua. Miguel Couto, № 128 - Anita Garibaldi - Joinville, SC - CEP.; 89202-190

Fone: 47 - 423.3367 - Resp.: Dr. José Carlos de Camargo - jcpsico@zaz.com.br

Centro Psicossocial para Álcool e Drogas - CAPS ad II

Rua Sebastião Cruz, no 89 - Centro - Blumenau, SC

Fone: 47 - 326.6906 - Resp.: Izoldes Terezinha Regalin

\section{São Paulo}


Resp.: Dr. Ronaldo Kobayashi

Centro de Atenção Psicossocial - CRIAD

Rua Tiradentes, 882 - Guanabara - Campinas, SP

CEP.: 13100-000 - Fone: 19 - 3236.5593

Coord.: Ângela Stockler Vilela

Espaço Fernando Ramos da Silva

Av. Ulisses Guimarães, 598 - Pq, Diadema - Diadema, SP _

CEP.: 09990-080 - Fone: 11 - 4057.7993

Resp.; Dr. Guilherme Fochi

Centro de Atenção Psicossocial Em Dependência Química

Rua Cavalheiro Petraglia, 80 - Vila Nova - Franca, SP - CEP.: 14053-027

Fone: $16-3721.6502$ / 3711.9000

Resp.: Maria das Graças Menezes Bruxellas

CAPSad II - Dr. Arnaldo Brandt

Rua Odilon de Moraes, 87 - Bom Clima - Guarulhos, SP - CEP.: 07196-250

Fone: 2080325 - Resp.: Solange Aparecida Bena - www.napad1@ig.com.br

Centro Especializado no Tratamento de Dependências ao Álcool e Drogas

Rua. Tenente Ary Aps, 304 - Vianelo - Jundiaí, SP - CEP.: 13207-110

Fone: 11 - 4522.4277 / 4522.6898 - ceadjund@ig.com.br

Resp.: Cláudio Jerônimo da Silva

Centro de Atenção Psicossocial à Dependência Química de Santo André

Rua Henrique Porchat, 44 - Vila Bastos - Santo André, SP - 09041-170

011-49905294 - - dcalves@canbrasnet.com.br

Coord.: Décio Castro Alves

Núcleo de Atenção Psicossocial para Farmacodependentes

Rua Pará, 1280 - Ribeirão Preto, SP

CEP.: 14060-440 - Fone: 16 - 622.2100

Coord.: Vera Lucia Alves Gomes de Carvalho

Seção Núcleo de Atenção ao Dependente - SENAT

Rua Paraíba, 110 - Pompéia - Santos, SP

CEP.: 11065-470 - Fone: 13 - 3237.2681 - sms-santos@ig.com.br

Resp.: Eustázio Alves Pereira Filho

Centro de Atenção Psicossocial - CAPSad II

Rua Sebastião Hummel, 785 - Centro - São José dos Campos, SP 
CEP.: 12209-530 - Fone: 12 - 3912-1033 - sedc@sjc.sp.gov.br

Resp.: Edna Lúcia de Souza Tralli

Centro de Atenção Psicossocial ad CRATOD

Rua Prates, 165 - Bom Retiro - São Paulo, SP - CEP.: 01121-000

Fone: 11 - 33267868/228.1109 / 227.3871 - crcratod@ig.com.br

Coord.: Dra. Luizemir Lago

Centro de Atenção Psicossocial Álcool e Drogas - CAPSad

Rua Monsenhor Claro, Q. 6, no 82 - Centro - Bauru, SP - CEP 17015-130

Fone: 14 - 235.1288 - Ref.: Dr. Sergio Sato

Centro de Referência de Farmacodependência - Jabaquara

Avenida Ceci, 2235 - Vila Mariana -São Paulo, SP - CEP.: 04065004

Fone; 11 - 275-3432 - anarosacm@hotmail.com

Coord.: Ana Rosa Cantinho Moreira

Unidade Comunitária de Álcool e Drogas - Jardim Nélia

Rua Itajuibe, 1910 - Itaim Paulista - São Paulo, SP

Fone: $11-6963.3802$

Resp.: Maria do Rosário Oliveira / Maria Carlota Mariano

\section{Centro de Referência de Farmacodependência - Santo Amaro}

Av. Adolfo Pinheiro, 1463 - São Paulo, SP

CEP.: 04733200 - Fone: 11 - 5522.4833 / 55233566 - jrmurisset@ig.com.br

Coord.: Dr. José Roberto Cardoso Murriset

Centro de Referência de Farmacodependência - Centro / Sé

Rua Frederico Alvarenga, 529 - Parque D. Pedro II - São Paulo, SP

CEP.: 01020-030 - Fones: 11- 3105.2645 / 32575155 -- R-196 / 32410901

Coord.: Dr. Alfredo Toscano Jr. - farmacodep.centro@ig.com.br

Centro de Atenção Psicossocial a Usuários de Substâncias Psicoativas - CAPSad II

Rua Marechal Deodoro, 96 - Centro - Marília, SP - CEP 17501-110

Fone: 14 - 421.1744 - Coord .: Adalberto Jesus Silva da Rosa 
Espaço Aberto - Centro de Prevenção e Atendimento de Dependência Química

Rua Purus, 79 - Jardim São José - Jacareí, SP - CEP.:

Fone: 3961-3343 - Coord.: Cristina Moraes

PROSAM - Associação Pró-Saúde Mental

Rua Heitor Penteado, 1448 - Sumaré, SP

CEP.: 15438-100 - Fone: 11 - 3862.1385

Coord.: Joel Coradete Jr.

Unidade de Referência em Álcool e Drogas Pirituba - Casa Azul

Rua Lino Pinho dos Santos, 203 - jardim Felicidade - São Paulo, SP

011 - 38352903 / FAX 38352905 - carmenaparecidacosta@ig.com.br

Coord.: Dra. Carmen Aparecida da Costa

Unidade Comunitária de Álcool e Drogas - Americanópolis

Cidade Ademar - Rua Cidade de Santos, 46 - Americanópolis - São Paulo, SP

Resp.: Dra. Gislaine Sacardo / 011-55621476

Dra. Elaine Fernandes / 92295792 / 69484620

\subsection{Associações de Redução de Danos}

\section{ABORDA - ASSOCIAÇÃO BRASILEIRA DE REDUTORES DE DANOS PRESIDENTE: MARCELO ARAÚJO \\ Avenida General Justo n. 275 SI.316 "B" Centro \\ 22021-130-Rio de Janeiro - RJ $\quad$ (21) 22404351/91289361 \\ e-mail.: crisanpa@yahoo.com.br \\ tempovento@yahoo.com.br}

REDUC - REDE BRASILEIRA DE REDUÇÃO DE DANOS

PRESIDENTE: MÔNICA GORGULHO

Alameda Madeira, 258 - Sala 604 - Alphaville

06454-010 - Barueri/SP

Tel:: (11) 4195-0335

Fax: (11) 4153-7697

e-mail: info@reduc.org

Endereço Eletrônico: http://www.reduc.org

\section{RELARD - REDE LATINO-AMERICANA DE REDUÇÃO DE DANOS} PRESIDENTE: SANDRA BATISTA

Rua Padre Anchieta, 1007 apto. 31

Curitiba - PR

CEP: $80430-060$

Tel: (41) 3244400 - 3363446 - 9192-0400

Fax: (41) 3245916

Endereço Eletrônico: flama51@terra.com.br

http://www.relard.org 
Rua Mestre Macedinho, n. .0141 - casa 07 - B. Nonoai

91720-600 - Porto Alegre, RS

Tel.: (51) 9164-2507 - 9164-2507

Fax: (51) 231-7114

e-mail: $\underline{\text { arede.rs@bol.com.br }}$

ASSOCIAÇÃO CATARINENSE DE REDUTORES DE DANOS

PRESIDENTE: MÁRIO HENRIQUE FRANCISCO DOS SANTOS

Rua Júlio Moura, n.․ 192 - sala 101 Centro

88020-150 - Florianópolis, SC

Tel.: (48) 9992-1901 ou 223-3719

e-mail.: acordasc1@bol.com.bf

mariohsc@hotmail.com.br

APRENDA - ASSOCIAÇÃO PAULISTA DE REDUTORES DE DANOS

PRESIDENTE: IVANI LUCI DIAS

Rua Saldanha Marinho, 3877 - Bairro Bom Jesus

15014-300 - São José do Rio Preto - SP

Tel.: (17) 234-3660

e-mail:

ASSOCIAÇÃO CARIOCA DE REDUÇÃO DE DANOS

PRESIDENTE: CRISTIANE MOEMA

Praia de Botafogo, n.o 316 - Sala 920

22250-040 - Rio de Janeiro, RJ

Tel.: (21) 25522761/94268850

e-mail.: crisanpa@yahoo.com.br

ABAREDA - ASSOCIAÇÃO BAIANA DE REDUTORES DE DANOS

PRESIDENTE: MARCOS MANSO

CETAD/UFBA

Rua Pedro Lessa, n.. 123 - Canela

40110-050 - Salvador, BA

Tel.: (71) 336-7943 - 336-8673 - 347-7284

e-mail.: abareda@bol.com.br

REDAMMIG - REDUTORES DE DANOS DE DANOS DE MINAS GERAIS

PRESIDENTE: CARLA SILVEIRA

Rua Além Paraíba $917-A$

31210-120 Bairro: Bonfim - Belo Horizonte, MG

Tel: (31) 3427266

e-mail:

MOVIMENTO METROPOLITANO DE REDUÇÃO DE DANOS

PRESIDENTE: DILSON CONCEIÇÃO STROŞSI

José de Alencar 1643 Apto.21

Bairro: Azenha

90880-481 - Porto Alegre - RS

Tel: (51) 9112-2971

e-mail: gravataids@ig.com.br

ASSOCIAÇÃO CEARENSE DE REDUÇÃO DE DANOS

Presidente: SÉRVULO PAULO SILVA CHAGAS

Rua Tianguá n. 158 Montese

60410-560 Fortaleza/CE

Fax(85) 491-0716

e-mail: $\underline{\text { rdfortaleza@terra.com.br }}$ 
ASSOCIAÇÃO PERNAMBUCANA DE REDUÇÃO DE DANOS

Presidente: ANA GLÓRIA MELCOP

Av. Domingos Ferreira, 636 sala 405 Ed. Clinical Center

Boa Viagem

51011-050 Recife - PE

(81) 3466-0527/1377 / 9126-8822

e-mail:amelcop@uol.com.br

REDE ACREANA DE REDUÇÃO DE DANOS

PRESIDENTE: ALVARO AUGUSTO DE ANDRADE MENDES

Rua Projetada, 074 Bairro Bosque

69914-610 Rio Branco - AC

(68) 223-9625/2236737

e-mail:prdacre@mdnet.com.br

REPARE - Rede Paranaense de Redução de Danos

PRESIDENTE: ROSA MARIA JERONYMO LIMA

Rua Rui Barbosa, 1786/603 Bairro Maracanã

85852-120 Foz do lguaçu - PR

Tel: (45) 30274214 - 9103-1618

chico@uol.com.br

ARD'POA - Associação de Redutores de Danos de Porto Alegre PRESIDENTE: TÂNIA REGINA OLIVEIRA TELLES

Rua Mário de Artagão N.13 Bairro: Partenom Vila Maria da Conceição

90680-080 Porto Alegre - RS

Tel: (51) 99118221

e-mail:Artpoa@hotmail.com

ACARD - ASSOCIAÇÃO DE REDUTORES DE DANOS DE PORTO ALEGRE PRESIDENTE: IZIS NASCIMENTO

NADIA A. CARPANEDO

Avenida Nossa Senhora da Penha 699/312 Torre B

Edifício Century Tower -Vitória - ES

Telefone:(28) 3345-9085 / 99893284

e-mail:ncarpanedo@hotmail.com.br

CENTRO DE CONVIVÊNCIA É DE LEI

PRESIDENTE: CRISTINA MARIA BRITES

VICE PRESIDENTE: Andrea Domanico

Rua 24 de maio $1164^{\circ}$ andar loja 37 centro- São Paulo

Cep- 01041-000

Telefone: 011-3337-6049

e-mail:conviveredelei@uol.com.br

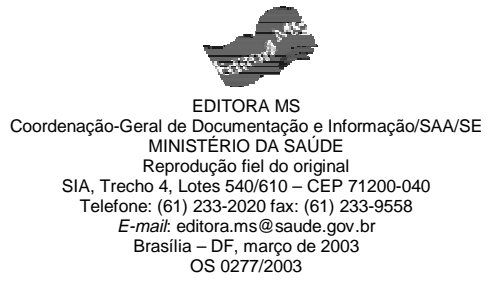

